\title{
Cost-effectiveness of Four Immunomodulatory Therapies for Relapsing-Remitting Multiple Sclerosis: A Markov Model Based on Long-term Clinical Data
}

\author{
Christopher Bell, MS; Jonathan Graham, MS; Stephanie Earnshaw, PhD; \\ MerriKay Oleen-Burkey, PhD; Jane Castelli-Haley, MBA; and Kenneth Johnson, MD
}

\begin{abstract}
BACKGROUND: Before the introduction of the immunomodulatory therapies for multiple sclerosis (MS), treatment options for MS consisted of symptomatic management (physical therapy and pharmacological treatment for symptom management). Symptomatic management for MS has been supplemented in the past decade by 2 new classes of immunomodulatory therapies that have been approved as first-line treatments for relapsing-remitting multiple sclerosis (RRMS): subcutaneous glatiramer acetate (SC GA) and $3 \beta$-interferons: intramuscular interferon $\beta$-1a (IM IFN $\beta$-1a), SC IFN $\beta$-1a, and SC IFN $\beta$-1b.

OBJECTIVE: To estimate the economic outcomes of 5 treatment strategies: symptom management alone, symptom management combined with SC GA, IM IFN $\beta 1-a$, SC IFN $\beta 1-a$, or SC IFN $\beta 1$-b in patients diagnosed with RRMS.

METHODS: A literature-based Markov model was developed to assess the cost-effectiveness of 5 treatment strategies for managing a hypothetical cohort of patients diagnosed with RRMS in the United States-4 immunomodulatory drug therapies and symptom management alone. Health states were based on the Kurtzke Expanded Disability Status Scale (EDSS), a widely accepted scale for assessing RRMS (higher EDSS scores = increased disease severity). Baseline relapse and disease progression transition probabilities for symptom management were obtained from natural history studies. Treatment effects of the immunomodulatory therapies were estimated by applying a percentage reduction to the symptom management transition probabilities for relapse ( $27 \%$ reduction) and disease progression (30\% reduction). Transition probabilities were subsequently adjusted to account for (1) the effects of neutralizing antibodies, specifically on relapse rates by assuming no additional therapy benefits after the second year of continuous therapy, and (2) treatment discontinuation. Therapy-specific data were obtained from

M ultiple sclerosis (MS) is a chronic, neurodegenerative inflammatory disease of the central nervous system. In the United States, the prevalence rate of MS is estimated to range between 85 and 177 cases per 100,000, translating to an overall prevalence of approximately $400,000 \cdot \cdot^{1-3}$ In a majority of patients (70\%), the onset of MS occurs during early adulthood (age 15-45 years), making MS one of the most common causes of neurological disability in young and middle-aged adults. ${ }^{4,5}$ Common symptoms of MS include fatigue, walking difficulties leading to reduced mobility, bowel/bladder disturbances, optic neuritis and other visual changes, changes in cognitive function, pain, sensory loss, and depression. ${ }^{6}$ Three main types of MS are generally recognized: (1) relapsing-remitting MS (RRMS), (2) secondary progressive MS (SPMS), and (3) primary progressive/relapsing MS (PPMS or PRMS). ${ }^{7,8}$ At disease onset, RRMS is diagnosed in approximately $80 \%$ to $85 \%$ of MS patients, with the remaining proportion of patients diagnosed with the primary progressive forms of MS (PPMS or PRMS). ${ }^{4,9,10}$ Among RRMS-diagnosed patients, a majority will progress to SPMS (50\% of patients will experience a gradual progression of disability within 10 years of the initial attack and $90 \%$ of patients will have progressive disease after 25 years). ${ }^{11}$
\end{abstract} clinical trials and long-term follow-up observational studies. Transitions among health states occurred in 1-month cycles for the lifetime of a patient. Costs (2005 US\$) and outcomes were discounted at 3\% annually.

RESULTS: The incremental cost per quality-adjusted life-year for the 4 immunomodulatory therapies is $\$ 258,465, \$ 303,968, \$ 416,301$, and $\$ 310,691$ for SC GA, IM IFN $\beta$-1a, SC IFN $\beta-1 \mathrm{a}$, and SC IFN $\beta$-1b, respectively, compared with symptom management alone. Sensitivity analyses demonstrated that results were sensitive to changes in utilities, disease progression rates, time horizon, and immunomodulatory therapy cost.

CONCLUSIONS: The pharmacoeconomic model determined that SC GA was the best strategy of the 4 immunomodulatory therapies used to manage MS and resulted in better outcomes than symptom management alone. Sensitivity analyses indicated that the model was sensitive to changes in a number of key parameters, and thus changes in these key parameters would likely influence the estimated cost-effectiveness results. Head-to-head randomized clinical trials comparing the immunomodulatory therapies for the treatment of MS are necessary to validate the projections from the pharmacoeconomic analyses, particularly since the results available today from the clinical trials do not account adequately for treatment dropouts.

KEYWORDS: Multiple sclerosis, Immunomodulatory therapy, Markov model, Cost-effectiveness

J Manag Care Pharm. 2007;13(3):245-61
Note: An editorial on the subject of this article appears on pages 287-89 of this issue.

\section{Authors}

CHRISTOPHER BELL, MS, is senior director, Health Economics, JONATHAN GRAHAM, MS, is a health economist, and STEPHANIE EARNSHAW, PhD, is global head, U.S., Health Economics, RTI-Health Solutions, Research Triangle Park, North Carolina; MERRIKAY OLEEN-BURKEY, PhD, is director, Outcomes Research and Medical Operations, and JANE CASTELLI-HALEY, MBA, is manager, Health Outcomes Research, Teva Neuroscience, Inc., Kansas City, Missouri; KENNETH JOHNSON, MD, is a professor of neurology and director, Maryland Center for Multiple Sclerosis, School of Medicine, University of Maryland, Baltimore, Maryland.

AUTHOR CORRESPONDENCE: Christopher Bell, MS, clo Stephanie Earnshaw, PhD, Global Head, U.S. Health Economics, RTI-Health Solutions, 200 Park Dr., PO Box 12194, Research Triangle Park, NC 27709. Tel: (919) 485-2730;

Fax: (919) 541-7222; E-mail: searnshaw@rti.org

Copyright $\odot$ 2007, Academy of Managed Care Pharmacy. All rights reserved. 


\section{Cost-effectiveness of Four Immunomodulatory Therapies for Relapsing-Remitting Multiple Sclerosis:}

A Markov Model Based on Long-term Clinical Data

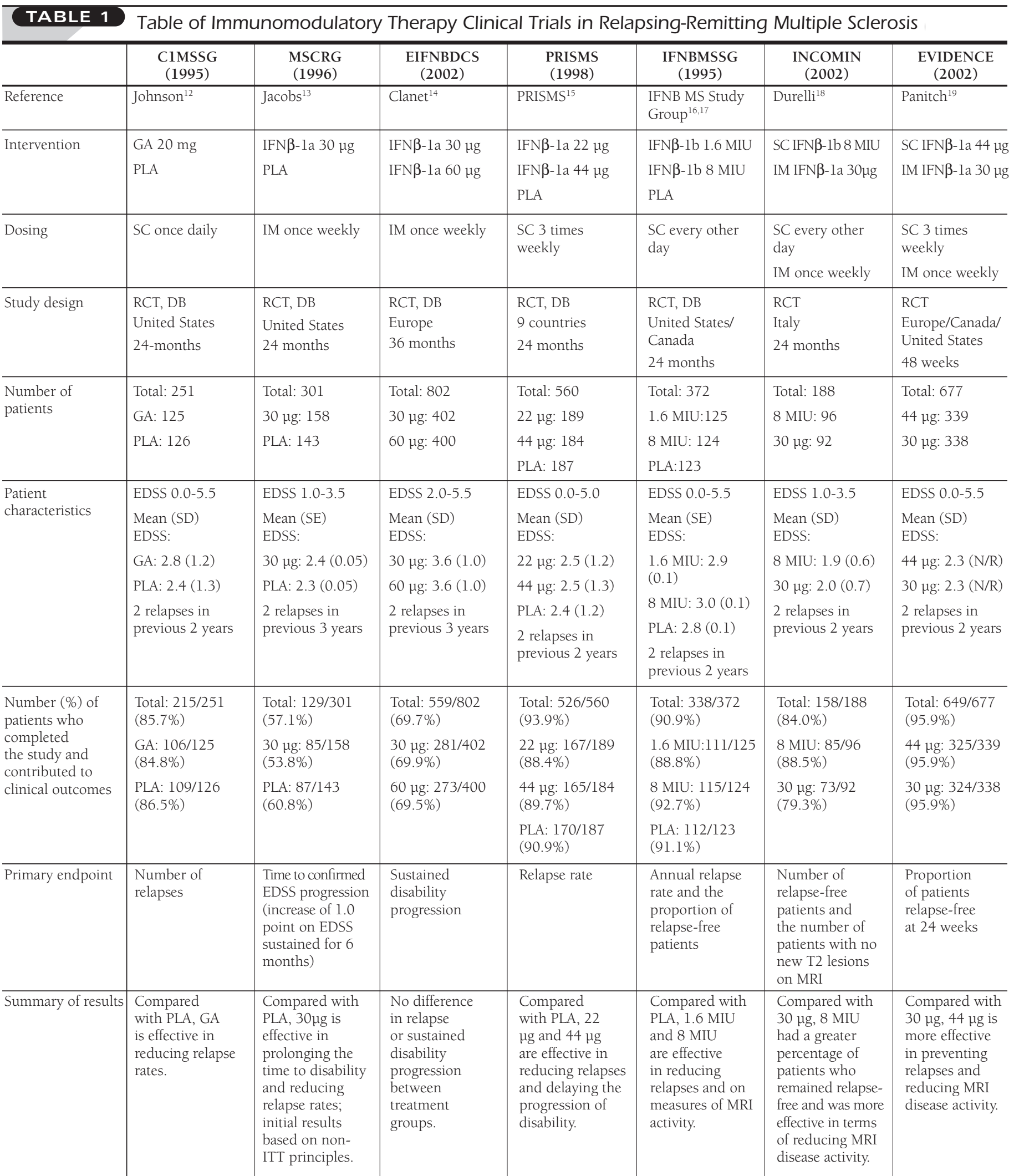




\section{Cost-effectiveness of Four Immunomodulatory Therapies for Relapsing-Remitting Multiple Sclerosis:}

A Markov Model Based on Long-term Clinical Data

\begin{tabular}{|c|c|c|c|c|c|c|c|}
\hline & $\begin{array}{l}\text { C1MSSG } \\
(1995)\end{array}$ & $\begin{array}{l}\text { MSCRG } \\
\text { (1996) }\end{array}$ & $\begin{array}{l}\text { EIFNBDCS } \\
\quad(2002)\end{array}$ & $\begin{array}{l}\text { PRISMS } \\
\text { (1998) }\end{array}$ & $\begin{array}{c}\text { IFNBMSSG } \\
(1995)\end{array}$ & $\begin{array}{l}\text { INCOMIN } \\
(2002)\end{array}$ & $\begin{array}{l}\text { EVIDENCE } \\
\quad(2002)\end{array}$ \\
\hline Relapse results ${ }^{6}$ & $\begin{array}{l}\text { Mean number } \\
\text { of relapses over } \\
2 \text { years: } \\
\text { GA: } 1.19 \\
\text { PLA: } 1.68 \\
\text { RR (vs. PLA): } \\
\text { GA }=0.71\end{array}$ & $\begin{array}{l}\text { Annual relapse } \\
\text { rate (all } \\
\text { patients): } \\
30 \mu \mathrm{g}: 0.67 \\
\text { PLA: } 0.82 \\
\text { RR (vs. PLA): } \\
30 \mu g=0.82 \\
\text { Annual relapse } \\
\text { rate (2-year } \\
\text { completers): } \\
30 \mu g: 0.61 \\
\text { PLA: } 0.90 \\
\text { RR (vs. PLA): } \\
30 \mu g=0.68\end{array}$ & $\begin{array}{l}\text { Annualized } \\
\text { relapse rate: } \\
30 \mu \mathrm{g}: 0.77 \\
60 \mu \mathrm{g}: 0.81\end{array}$ & $\begin{array}{l}\text { Relapse rate over } \\
2 \text { years: } \\
22 \mu \mathrm{g}: 1.82 \\
44 \mu \mathrm{g}: 1.73 \\
\text { PLA: } 2.56 \\
\text { RR (vs. PLA): } \\
22 \mu \mathrm{g}=0.71 \\
44 \mu \mathrm{g}: 0.68\end{array}$ & $\begin{array}{l}\text { Annual relapse } \\
\text { rate over } 2 \text { years: } \\
\text { 1.6 MIU: } 1.17 \\
8 \text { MIU: } 084 \\
\text { PLA: } 1.27 \\
\text { RR (vs. PLA): } \\
\text { 1.6 MIU = } 0.92 \\
8 \text { MIU = } 0.66 \\
\text { Relapse-free } \\
\text { patients after } \\
2 \text { years: } \\
\text { 1.6 MIU: } 23 \% \\
8 \text { MIU: } 36 \% \\
\text { PLA: } 18 \%\end{array}$ & $\begin{array}{l}\text { Relapse-free } \\
\text { patients after } \\
2 \text { years: } \\
8 \text { MIU: } 51 \% \\
30 \mu \mathrm{g}: 36 \%\end{array}$ & $\begin{array}{l}\text { Relapse-free } \\
\text { patients after } \\
24 \text { weeks: } \\
44 \mu \mathrm{g}: 75 \% \\
30 \mu \mathrm{g}: 63 \% \\
\text { Relapse-free } \\
\text { patients after } \\
48 \text { weeks: } \\
44 \mu \mathrm{g}: 62 \% \\
30 \mu \mathrm{g}: 52 \%\end{array}$ \\
\hline $\begin{array}{l}\text { Disease } \\
\text { progression } \text { results }^{6}\end{array}$ & $\begin{array}{l}\text { Patients with } \\
\text { increase of } 1.0 \\
\text { point on EDSS } \\
\text { (unsustained): } \\
\text { GA: } 20.8 \% \\
\text { PLA: } 28.8 \%\end{array}$ & 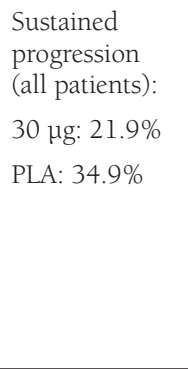 & $\begin{array}{l}\text { Sustained } \\
\text { progression } \\
\text { by } 36 \text { months } \\
\text { (increase of } 1.0 \\
\text { point on EDSS } \\
\text { sustained for } \\
6 \text { months): } \\
30 \mu \mathrm{g}: 37 \% \\
60 \mu \mathrm{g}: 37 \%\end{array}$ & $\begin{array}{l}\text { Time (months) } \\
\text { to progression } \\
\text { of disability } \\
\text { (increase of } 1.0 \\
\text { point on EDSS } \\
\text { sustained for } \\
3 \text { months): } \\
22 \mu \mathrm{g}: 18.5 \\
44 \mu \mathrm{g}: 21.3 \\
\text { PLA: } 11.9\end{array}$ & N/A & $\begin{array}{l}\text { Confirmed } \\
\text { progression } \\
\text { of disability } \\
\text { (increase of } 1.0 \\
\text { point on EDSS } \\
\text { sustained for } \\
6 \text { months): } \\
8 \text { MIU: } 30 \% \\
30 \mu \mathrm{g}: 15 \%\end{array}$ & $\begin{array}{l}\text { Confirmed } \\
\text { progression } \\
\text { of disability } \\
\text { (increase of } 1.0 \\
\text { point on EDSS } \\
\text { sustained for } \\
6 \text { months): } \\
8 \mathrm{MIU}: 6 \% \\
30 \mu \mathrm{gg}: 8 \%\end{array}$ \\
\hline $\begin{array}{l}\text { Study extensions } \\
\text { (\% of patients } \\
\text { initially } \\
\text { randomized } \\
\text { to study drug } \\
\text { completing } \\
\text { extension) }\end{array}$ & $\begin{array}{l}35 \text { months } \\
(77.6 \%)^{20} \\
6 \text { years }(61.6 \%)^{24} \\
8 \text { years }(57.6 \%)^{25} \\
10 \text { years }(51.2 \%)^{28}\end{array}$ & $\begin{array}{l}8 \text { years (N/A, } \\
\text { LTFU) })^{94}\end{array}$ & 4 years $(55.6 \%)^{21}$ & $\begin{array}{l}4 \text { years }(78.8 \%)^{22} \\
6 \text { years }(50.1 \%)^{26} \\
8 \text { years (N/A, } \\
\text { LTFU) }\end{array}$ & $\begin{array}{l}5 \text { years }(44.2 \%)^{23} \\
16 \text { years (N/A, } \\
\text { LTFU) })^{95}\end{array}$ & N/A & N/A \\
\hline
\end{tabular}

C1MSSG = Copolymer-1 Multiple Sclerosis Study Group; DB=double blind; EDSS=Expanded Disability Status Scale (Kurtzke); EIFNBDCS=European IFN及-1 a DoseComparison Study; EVIDENCE = Evidence of Interferon Dose-Response: European North American Comparative Efficacy; GA=glatiramer acetate; IFN=interferon; IFNBMSSG =Interferon Beta Multiple Sclerosis Study Group; IM =intramuscular; INCOMIN = Independent Comparison of Interferon; ITT =intent to treat;

LTFU = long-term follow-up visit; MIU = million international units; $M R I=$ magnetic resonance imaging; $M S=$ multiple sclerosis; MSCRG=Multiple Sclerosis Collaborative Research Group; N/A = not available; N/R = not reported; PLA = placebo; PRISMS = Prevention of Relapses and Disability by Interferon $\beta$-1a Subcutaneously in Multiple Sclerosis; $R C T=$ randomized clinical trial; $R R=$ relative risk; $S C=$ subcutaneous; $\mu \mathrm{g}=$ micrograms.

Before the immunomodulatory therapies for MS were introduced, treatment options for MS consisted of symptomatic management (physical therapy and pharmacological treatment for symptom management). Symptomatic management for MS has been supplemented in the past decade by 2 new classes of immunomodulatory therapies that have been approved as first-line treatments for RRMS: subcutaneous glatiramer acetate (SC GA) (Copaxone) and $3 \beta$-interferons: intramuscular interferon $\beta$-la (IM IFN $\beta$-la [Avonex]), SC IFN $\beta$-la (Rebif), and SC IFN $\beta$-1b (Betaseron). Evidence from randomized clinical trials ( $1-2$ years $)^{12-19}$; prospective extensions of the clinical trials (2-5 years $)^{20-23}$; and long-term follow-up studies of patients initially enrolled in clinical trials ${ }^{24-27}$ (one of which extends beyond 10 years $^{28}$ ) have shown that there is good evidence demonstrating the benefits of immunomodulatory therapies in reducing relapse rates, slowing the progression of disability, and reducing MS disease activity (Table 1 ).

However, the use of the immunomodulatory therapies in everyday clinical practice has been a topic of substantial debate. The National Institute for Clinical Excellence (NICE) determined 


\section{Cost-effectiveness of Four Immunomodulatory Therapies for Relapsing-Remitting Multiple Sclerosis: A Markov Model Based on Long-term Clinical Data}

\section{FIGURE 1 Schematic Representation} of the Markov Model

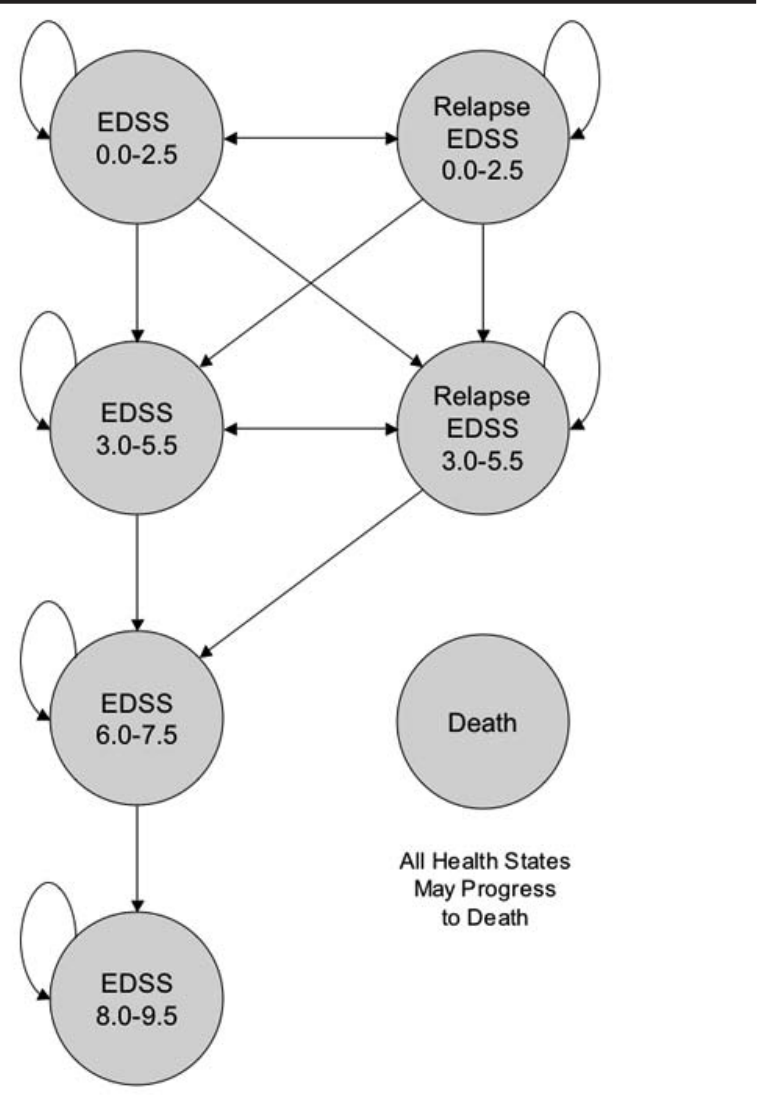

EDSS=Expanded Disability Status Scale (Kurtzke).

that "...on the balance of their clinical and cost-effectiveness, neither beta interferon nor glatiramer acetate is recommended..." and those therapies were provided to patients only after the Department of Health and the respective manufacturers agreed to a risk-sharing scheme. ${ }^{29,30}$ In contrast to NICE's guidance, some clinical practice guidelines have recommended the immunomodulatory therapies for the treatment of MS. ${ }^{31}$ The selection of specific therapies is based on individual patient characteristics (e.g., disease severity, patient compliance) and treatment characteristics (e.g., efficacy, incidence of neutralizing antibodies [NAbs], side effects).

The socioeconomic burden of MS is substantial given the debilitating nature of this chronic, progressive, and lifelong condition that affects individuals in the most productive years of life. Drug acquisition cost for the immunomodulatory therapies was estimated to exceed $\$ 16,000$ per patient per year in 2006 , a significant expenditure for health care payers. ${ }^{32-34}$ The annual cost of illness of MS (in 1994 US\$) is estimated to be between $\$ 6.8$ and $\$ 13.6$ billion, composed largely of indirect costs for formal/informal care and lost earnings. ${ }^{35}$ Patwardhan et al. ${ }^{36}$ assessed the link between disability levels and costs and found that costs rose at an exponential rate with increasing MS disability levels, a finding that was consistent with previously published studies. ${ }^{37-39}$ Given this evidence of increasing costs (direct and indirect) with increasing disease severity, we believe the ability of the immunomodulatory therapies to reduce relapse rates and slow the progression of the MS may assist in reducing resource use and may, in turn, help to offset the cost of these therapies.

Cost-effectiveness and cost-utility analyses (CEA/CUAs) are useful tools to assess the tradeoff between the added costs and potential benefits (e.g., improved patient outcomes) of new therapies. In the current environment of cost-consciousness and limited health care resources, CEA/CUA affords decision makers an opportunity to evaluate new therapies from an economic perspective and quantify the budgetary implications of adopting such therapies. A majority of the published CEA/CUA evaluations of immunomodulatory therapies for MS have been conducted from perspectives outside the United States.,.$^{30,40-45}$ In a recent U.S.-based CUA evaluation, immunomodulatory therapy for the treatment of nonprimary, progressive MS (e.g., RRMS and SPMS) was compared with no treatment over a 10-year time horizon. ${ }^{46}$ Cost-effectiveness results from this analysis, as well as previously published CUA evaluations, were considerably higher than the arbitrary and commonly referenced benchmark of $\$ 50,000$ per quality-adjusted life-year (QALY). ${ }^{47}$

Recent published literature on the impact of the immunomodulatory therapies in MS has provided key data that have not been previously used in CEA/CUA evaluations. Specifically, long-term follow-up data of patients initially enrolled in clinical trials have been published, ${ }^{24-28}$ one of which, for SC GA, extended beyond 10 years. ${ }^{28}$ In previous CEA/CUA evaluations, long-term treatment outcomes (e.g., treatment effects and discontinuation rates) were extrapolated over time based primarily on data from short-term clinical trials. In addition to long-term follow-up data, there has been focus on the development of NAbs among patients prescribed $\beta$-interferons, which may inhibit or "neutralize" the effectiveness of $\beta$-interferon treatment. ${ }^{48}$

Because of data limitations, previous models have made assumptions regarding the impact of $\beta$-interferons on treatment effects (e.g., constant treatment effects over time), which, in turn, made it difficult to examine the impact that NAbs might have on cost-effectiveness. With the availability of long-term data, costeffectiveness analysis of various therapies in the presence of these clinical markers can be made more appropriately. In this regard, we examine the cost-effectiveness of 5 treatment strategies in patients diagnosed with RRMS (symptom management alone and in combination with SC GA, IM IFN $\beta-1$ a, SC IFN $\beta-1$ a, or IM IFN $\beta$-1b). Cost-effectiveness results (symptom management vs. the 4 immunomodulatory therapies) were reported in terms of cost per QALY gained as well as cost per outcome achieved 


\section{Cost-effectiveness of Four Immunomodulatory Therapies for Relapsing-Remitting Multiple Sclerosis: A Markov Model Based on Long-term Clinical Data}

(e.g., cost per year spent relapse free or cost per year spent in less severe disease health states), thus providing decision makers relevant data with which to evaluate the cost-effectiveness of the 4 immunomodulatory therapies versus symptom management in treating RRMS.

\section{Methods}

\section{Model Description}

We developed a Markov model to assess the cost-effectiveness of 5 treatment strategies to manage a hypothetical cohort of patients diagnosed with RRMS in the United States. The strategies were symptom management alone (e.g., physical therapy/ exercise and pharmacological treatment [e.g., corticosteroids for relapse, tizanidine for spasticity, and modafinil for fatigue]) and symptom management in combination with 1 of the following immunomodulatory therapies: SC GA, IM IFN $\beta$-1a, SC IFN $\beta$-la, or SC IFN $\beta-1 b$. The clinical course of RRMS (e.g., disease progression and relapse) was modeled in terms of the Kurtzke Expanded Disability Status Scale (EDSS). ${ }^{49}$ Specifically, 7 EDSS health states were modeled (Figure 1):

1. EDSS 0.0-2.5: no or few limitations in mobility

2. EDSS 3.0-5.5: moderate limitations in mobility

3. EDSS 6.0-7.5: walking aid or wheelchair required

4. EDSS 8.0-9.5: restricted to bed

5. Death (natural causes or EDSS 10)

6. Relapse EDSS 0.0-2.5: relapse with a change in disability within EDSS 0.0-2.5

7. Relapse EDSS 3.0-5.5: relapse with a change in disability within EDSS 3.0-5.5

Transitions among the health states occurred in 1-month cycles. The baseline time horizon of the model was assumed to be lifetime in order to capture the full benefits of immunomodulatory therapy. Costs and outcomes were estimated from the societal perspective and were discounted at 3\% per annum. ${ }^{50}$ All costs were reported in 2005 U.S. dollars. The natural history of MS disease progression, clinical efficacy of MS therapies, mortality, resource use, costs, and utilities were obtained from the published literature. The model calculated the following outcomes: average number of years spent in EDSS 0.0-5.5; average number of years spent relapse free; life-years; QALYs; total costs and costs by component (i.e., immunomodulatory therapy cost, MS-related medical costs [e.g., drugs for symptom management], and lost worker productivity costs); and incremental cost-effectiveness ratios comparing symptom management alone with symptom management combined with each of the 4 immunomodulatory therapies. Model parameters were varied in sensitivity analyses.

A number of underlying assumptions were adopted for the base-case model:

1. A Web survey of patients (aged $\geq 18$ years) treated with immunomodulatory therapy in the United States and enrolled in a patient support program was used to determine the percentage of patients entering the model among the 4 nonrelapse EDSS health states ${ }^{51}$ (Table 2). The survey, based on previous surveys conducted in the United States and Europe, ${ }^{52,53}$ was completed by 711 MS patients and collected data such as disease information (e.g., type of MS, therapy used), quality of life, resource use, and associated costs (direct and indirect). The majority of surveyed patients were in the lower EDSS health states (e.g., EDSS <6.0), which represents RRMS patients eligible for immunomodulatory therapy, and the overall distribution was relatively consistent with previously published surveys among patients diagnosed with MS. ${ }^{54-57}$ Sensitivity analyses were conducted to assess varying patient distributions (e.g., 100\% of patients start in EDSS 0.0-2.5 health state).

2. The point at which patients transformed from RRMS (characterized by clearly defined relapses with at least partial recovery of deficits and lack of disease progression between relapses) to SPMS (characterized by less frequent relapses and deficits that begin to progress even between relapses) was not specified in the model, as the precise time at which this transformation takes place is not clearly defined. Rather, the model assumed that this transformation took place between EDSS 3.0-5.5 and EDSS 6.0-7.5. Corresponding to this assumption, the model assumed that relapses occurred only in patients in the lower EDSS health states (EDSS 0.0-5.5) and that the rate of disease progression increased in the higher EDSS health states (EDSS 6.0-9.5).

3. The model assumed that, per product labeling, only RRMS patients were eligible for and received immunomodulatory therapy, corresponding to patients in the lower EDSS health states (i.e., EDSS 0.0-5.5).

4. Switching among the immunomodulatory therapies was not permitted in the model. Patients discontinuing immunomodulatory therapy were assigned the transition probabilities for relapse and disease progression used in the symptom management arm. Patients who discontinued therapy were not permitted to reinitiate therapy.

5. The model assumed that nonrelapse-related EDSS scores do not improve over time; therefore, patients transitioned to the next, more severe health state, 1 health state at a time, corresponding to a progression in disease severity (e.g., EDSS 0.0-2.5 to EDSS 3.0-5.5).

The base-case parameter inputs, values, and additional assumptions are detailed in the next sections and are summarized in Table 2.

\section{Clinical Course of MS}

Relapse and disease progression transition probabilities within the symptom management arm were obtained from published natural history studies (relapse rates, $4,58,59$ disease progression ${ }^{11,60}$ ), as reported in a previous MS cost-effectiveness model ${ }^{46}$ Mortality due to natural causes was assumed to occur at any cycle in the model based on age-specific, all-cause mortality rates. ${ }^{61}$ Mortality due to MS was assumed to occur only after patients had progressed through all EDSS health states 
TABLE 2 Summary of Parameters and Values Used in the Base-Case Markov Model

\begin{tabular}{|c|c|c|c|c|}
\hline \multirow{3}{*}{$\begin{array}{l}\text { Parameter Description } \\
\text { Initial patient distribution among EDSS health states } \\
\text { EDSS } 0.0-2.5\end{array}$} & \multirow{3}{*}{$\begin{array}{c}\begin{array}{c}\text { Estimate for } \\
\text { Base-Case Model }\end{array} \\
26.4 \%\end{array}$} & \multicolumn{2}{|c|}{$\begin{array}{c}\text { Range for Sensitivity Analysis } \\
( \pm 25 \% \text { Unless Indicated Otherwise) }\end{array}$} & \multirow{6}{*}{$\frac{\text { Reference }}{{\text { Oleen-Burkey [abstract }]^{51}}}$} \\
\hline & & Scenario 1 & Scenario 2 & \\
\hline & & $100.0 \%$ & $25.0 \%$ & \\
\hline EDSS 3.0-5.5 & $58.7 \%$ & $0.0 \%$ & $25.0 \%$ & \\
\hline EDSS 6.0-7.5 & $13.8 \%$ & $0.0 \%$ & $25.0 \%$ & \\
\hline EDSS 8.0-9.5 & $1.1 \%$ & $0.0 \%$ & $25.0 \%$ & \\
\hline $\begin{array}{l}\text { Monthly probability of disease progression } \\
\text { (symptom management) }\end{array}$ & & \multirow{5}{*}{\multicolumn{2}{|c|}{$\mathrm{N} / \mathrm{C}$}} & $\begin{array}{l}\text { Weinshenker }{ }^{11} \text {; Runmarker }{ }^{60} \text {; } \\
\text { Prosser }{ }^{46}\end{array}$ \\
\hline EDSS $0.0-2.5$ to $3.0-5.5$ & 0.004438 & & & \\
\hline EDSS $3.0-5.5$ to $6.0-7.5$ & 0.009189 & & & \\
\hline EDSS $6.0-7.5$ to $8.0-9.5$ & 0.003583 & & & \\
\hline EDSS 8.0-9.5 to 10 (death) & 0.000952 & & & \\
\hline $\begin{array}{l}\text { Monthly probability of relapse (symptom } \\
\text { management) }\end{array}$ & 0.075500 & \multicolumn{2}{|c|}{$\mathrm{N} / \mathrm{C}$} & $\begin{array}{l}\text { Goodkin }^{58} ; \text { Weinshenker, } \\
\text { Prosser }^{46}\end{array}$ \\
\hline $\begin{array}{l}\text { Treatment effects of SC GA and } \beta \text {-interferons, } \\
\% \text { reduction in: } \\
\text { Probability of disease progression } \\
\text { Probability of relapse }\end{array}$ & $\begin{array}{l}30 \% \\
27 \%\end{array}$ & \multicolumn{2}{|c|}{$\begin{array}{r}12.5 \%-47.5 \% \\
8.8 \%-45.2 \%\end{array}$} & Filippini $^{64} ;$ Simpson $^{90} ;$ Khan $^{66}$ \\
\hline $\begin{array}{l}\text { Incidence of NAbs } \\
\text { IM IFN } \beta \text {-la } \\
\text { SC IFN } \beta-1 \mathrm{a} \\
\text { SC IFN } \beta-1 b\end{array}$ & $\begin{array}{r}2.2 \% \\
17.4 \% \\
36.4 \%\end{array}$ & \multicolumn{2}{|c|}{$\begin{array}{c}1.7 \%-2.8 \% \\
13.1 \%-21.8 \% \\
27.3 \%-45.5 \%\end{array}$} & $\begin{array}{l}\text { Rossman }^{48} ; \text { IFNB MS } \\
\text { Study Group } \\
\text { Study Group }{ }^{16} ; \text { PRISMSean } \\
\text { Stis; } \\
\text { SPECTRIMS } \\
\text { Jacobs }^{13,98} \text {; } \text { Clanet }^{14} ; \text { Cohen }^{99}\end{array}$ \\
\hline $\begin{array}{l}\text { Monthly drug acquisition costs (WAC), } 2005 \text { U.S.\$ } \\
\text { SC GA } \\
\text { IM IFN } \beta-1 \mathrm{a} \\
\text { SC IFN } \beta-1 \mathrm{la} \\
\text { SC IFN } \beta-1 \mathrm{~b}\end{array}$ & $\begin{array}{l}\$ 1,258.20 \\
\$ 1,275.00 \\
\$ 1,469.64 \\
\$ 1,264.85\end{array}$ & $\begin{array}{r}\$ 94 \\
\$ 95 \\
\$ 1,10 \\
\$ 94\end{array}$ & $\begin{array}{r}72.75 \\
93.75 \\
337.05 \\
81.06\end{array}$ & Red Book ${ }^{33}$ \\
\hline
\end{tabular}

(i.e., only patients in the EDSS 8.0-9.5 health state could transition to EDSS 10, which is death). This assumption was consistent with a previous model ${ }^{46}$ that was based on data indicating that nearly $90 \%$ of MS patients were significantly disabled (e.g., unable to walk) before death. ${ }^{62}$ These data are presented in Table 2.

\section{Treatment Effects of SC GA and the $\beta$-Interferons}

Treatment effects associated with the immunomodulatory therapies were estimated by adjusting (via a percentage reduction) the probabilities of relapse and disease progression used in the symptom management arm of the model. Relapse and disease progression rates over time were obtained from randomized clinical trials (SC GA, ${ }^{12}$ IM IFN $\beta-1 a,{ }^{13,14,63}$ SC IFN $\beta$ $1 a,{ }^{15}$ SC IFN $\left.\beta-1 b^{16,17}\right)$; prospective extensions of the clinical trials (SC GA, ${ }^{20}$ IM IFN $\beta-1 a,{ }^{21}$ SC IFN $\beta-1 a,{ }^{22}$ SC IFN $\beta-1 b^{23}$ ); and long-term follow-up studies (SC GA, ${ }^{28}$ SC IFN $\beta-1 a^{26}$ ).
Relapse and disease progression rates were then mapped and fitted to prediction curves over time to estimate the long-term treatment effects of SC GA and the $\beta$-interferons (relapse: Figure 2; disease progression: Figures 3 and 4 ).

Toaccount for theinherent differences between the randomized clinical trials (e.g., patient population, primary endpoint), a fixed patient population was assumed for the base- case model. In particular, all patients entered the model on the basis of a fixed EDSS distribution (Table 2). Furthermore, short-term outcomes were modeled by assuming, for all immunomodulatory therapies, a single percentage reduction for relapse and disease progression in the first 2 years of therapy (Table 2). This assumption was based on data from several published review papers ${ }^{64-66}$ that indicated annual relapse and disease progression rates in the randomized clinical trials were similar among therapies. In subsequent years of the model, treatment effects were estimated based on the long-term, immunomodulatory-specific prediction 


\section{Cost-effectiveness of Four Immunomodulatory Therapies for Relapsing-Remitting Multiple Sclerosis:}

A Markov Model Based on Long-term Clinical Data

\section{TABLE 2}

Summary of Parameters and Values Used in the Base-Case Markov Model (continued)

\begin{tabular}{|c|c|c|c|c|c|c|}
\hline Parameter Description & $\begin{array}{c}\text { Estimate for } \\
\text { Base-Case Model }\end{array}$ & \multicolumn{4}{|c|}{$\begin{array}{c}\text { Range for Sensitivity Analysis } \\
( \pm 25 \% \text { Unless Indicated Otherwise })\end{array}$} & Reference \\
\hline Health state-specific MS-related costs (monthly) & & & Oleen-Burkey [abstract] $]^{51}$ \\
\hline EDSS $0.0-2.5$ & $\$ 433.26$ & \multicolumn{4}{|c|}{$\$ 324.95-\$ 541.58$} & \\
\hline EDSS 3.0-5.5 & $\$ 838.8 .3$ & \multicolumn{4}{|c|}{$\$ 629.12-\$ 1,048.54$} & \\
\hline EDSS $6.0-7.5$ & $\$ 1,990.02$ & \multicolumn{4}{|c|}{$\$ 1,492.52-\$ 2,487.53$} & \\
\hline EDSS 8.0-9.5 & $\$ 3,499.59$ & \multicolumn{4}{|c|}{$\$ 2,624.69-\$ 4,374.49$} & \\
\hline Relapse EDSS 0.0-2.5 & $\$ 427.98$ & \multicolumn{4}{|c|}{$\$ 320.99-\$ 534.97$} & \\
\hline Relapse EDSS 3.0-5.5 & $\$ 1,094.80$ & \multicolumn{4}{|c|}{$\$ 821.10-\$ 1,368.50$} & \\
\hline Monthly cost of lost worker productivity & & \multicolumn{2}{|c|}{ Scenario 1} & \multicolumn{2}{|c|}{ Scenario 2} & \multirow[t]{6}{*}{ Lichtenberg $^{74} ;$ Lage $^{75} ;$ Busche $^{7}$} \\
\hline $\begin{array}{l}\text { (no. of days missed } x \text { hourly wage } \mathrm{x} \% \text { of } \\
\text { patients employed) } \\
\text { Symptom management }\end{array}$ & $\$ 154.74$ & \multicolumn{2}{|l|}{$\mathrm{N} / \mathrm{C}$} & \multicolumn{2}{|c|}{$\$ 116.06-\$ 193.43$} & \\
\hline SC GA & $\$ 109.39$ & \multicolumn{2}{|c|}{$\$ 84.94-\$ 133.82$} & \multicolumn{2}{|c|}{$\$ 82.05-\$ 136.74$} & \\
\hline IM IFN $\beta-1 \mathrm{a}$ & $\$ 167.40$ & \multicolumn{2}{|c|}{$\$ 158.04-\$ 176.77$} & \multicolumn{2}{|c|}{$\$ 125.55-\$ 209.26$} & \\
\hline SC IFN $\beta-1 \mathrm{a}$ & $\$ 167.40$ & \multicolumn{2}{|c|}{$\$ 158.04-\$ 176.77$} & \multicolumn{2}{|c|}{$\$ 125.55-\$ 209.26$} & \\
\hline SC IFN $\beta-1 b$ & $\$ 162.63$ & \multicolumn{2}{|c|}{$\$ 159.47-\$ 165.79$} & \multicolumn{2}{|c|}{$\$ 121.97-\$ 203.29$} & \\
\hline Utility weights & & Scenario 1 & Scer & rio 2 & Scenario 3 & \multirow[t]{6}{*}{ Prosser $^{46} ;$ Kobelt $^{77} ;$ Kobelt $^{52}$} \\
\hline EDSS $0.0-2.5$ & 0.824 & $0.618-1.000$ & & & $\mathrm{~N} / \mathrm{C}$ & \\
\hline EDSS $3.0-5.5$ & 0.679 & $0.509-0.849$ & & & $\mathrm{~N} / \mathrm{C}$ & \\
\hline EDSS $6.0-7.5$ & 0.533 & $0.400-0.666$ & & & N/C & \\
\hline EDSS 8.0-9.5 & 0.491 & $0.368-0.614$ & & & $\mathrm{~N} / \mathrm{C}$ & \\
\hline Utility decrement associated with relapse & 0.094 & $0.071-0.118$ & & & $0.071-0.118$ & \\
\hline \multicolumn{7}{|c|}{$\begin{array}{l}\text { EDSS = Expanded Disability Status Scale (Kurtzke); EDSS 0.0-2.5=no MS symptoms to minimal disability in } 2 \text { functional areas; EDSS } 3.0-5.5=\text { moderate disability in } \\
1 \text { functional area or mild disability in up to } 4 \text { areas to disability severe enough to preclude full daily activities; EDSS } 6.0-7.5=\text { intermittent or unilateral constant assistance } \\
\text { required to walk } 100 \text { meters to restricted to wheelchair; EDSS 8.0-9.5= restricted to bed with many self-care functions retained to requiring assistance for all activities of } \\
\text { daily living; GA=glatiramer acetate; IFN =interferon; IM = intramuscular; MS = multiple sclerosis; N/A=not applicable; NAbs=neutralizing antibodies; N/C=no change; } \\
S C=\text { subcutaneous; symptom management = symptomatic management alone; WAC= wholesale acquisition cost. }\end{array}$} \\
\hline
\end{tabular}

curves. Sensitivity analyses were performed to assess the impact of varying the percentage reduction adjustments.

To account for the effect of NAbs, the probabilities of relapse for patients in the $\beta$-interferon arms of the model were subsequently adjusted. The model assumed that NAbs would affect the probability of relapse and would occur only after the second year of continuous interferon treatment. ${ }^{67-69}$ The incidence of NAbs was obtained from the published literature ${ }^{48}$ and was used to calculate an adjusted probability of relapse that reflected a weighted average of NAb-positive (NAb+) and NAbnegative (NAb-) patients. A conservative approach to modeling the impact of NAbs was adopted, where NAb+ patients (titer $\geq 20$ ) experienced a probability of relapse equal to that of the year-2 probability in each subsequent year of the model, and $\mathrm{NAb}$ - patients experienced a probability of relapse equal to that predicted by the fitted curve described previously. The model did not consider dose escalation of the $\beta$-interferons in response to NAbs.
The probabilities of relapse (adjusted for NAbs) and disease progression associated with the immunomodulatory therapies were also adjusted to account for patients who discontinued therapy. Rates of discontinuation were obtained from the published clinical trials and long-term follow-up studies; a relative 3\% annual discontinuation rate was assumed in the event data were not available. ${ }^{30}$ Patients who discontinued therapy were assigned the probabilities of relapse and disease progression used in the symptom management arm of the model. Similar to the calculation performed for NAbs, the adjusted probability of relapse and disease progression reflected a weighted average of patients continuing and discontinuing therapy. The fitted curves for the long-term treatment effects of the immunomodulatory therapies adjusted for NAbs and discontinuation are reflected in Figures 2-4. The figures indicate an immediate shortterm reduction in relapse and disease progression rates and a stabilization in rates (relapse and disease progression) over the long term. 


\section{Cost-effectiveness of Four Immunomodulatory Therapies for Relapsing-Remitting Multiple Sclerosis:}

A Markov Model Based on Long-term Clinical Data
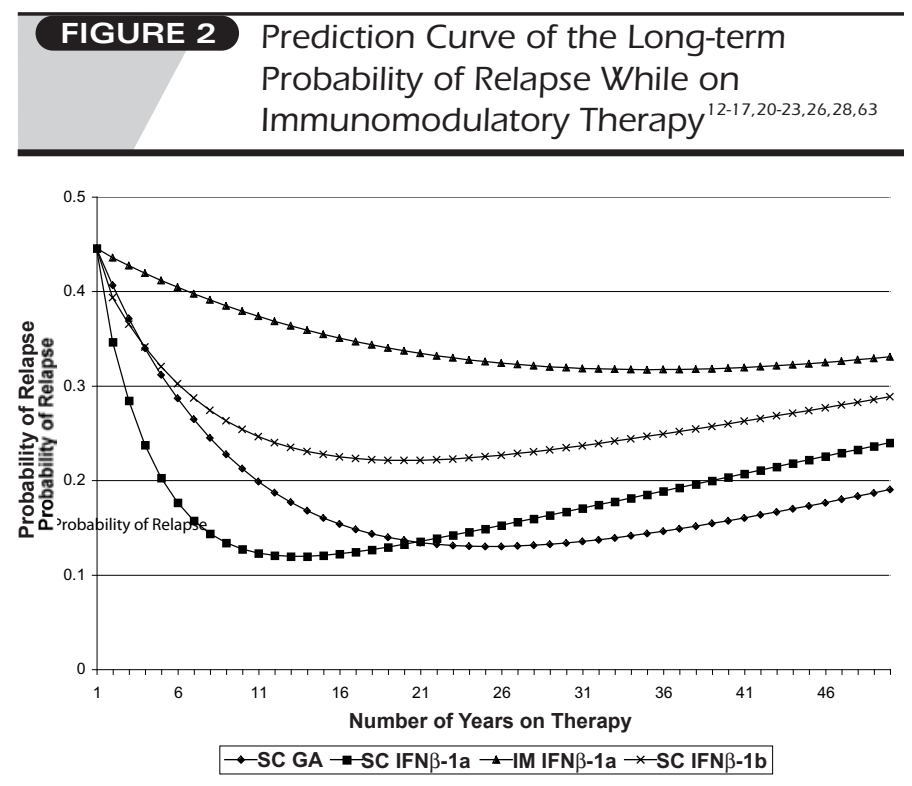

GA= glatiramer acetate; IFN= interferon; IM = intramuscular; $S C=$ subcutaneous.

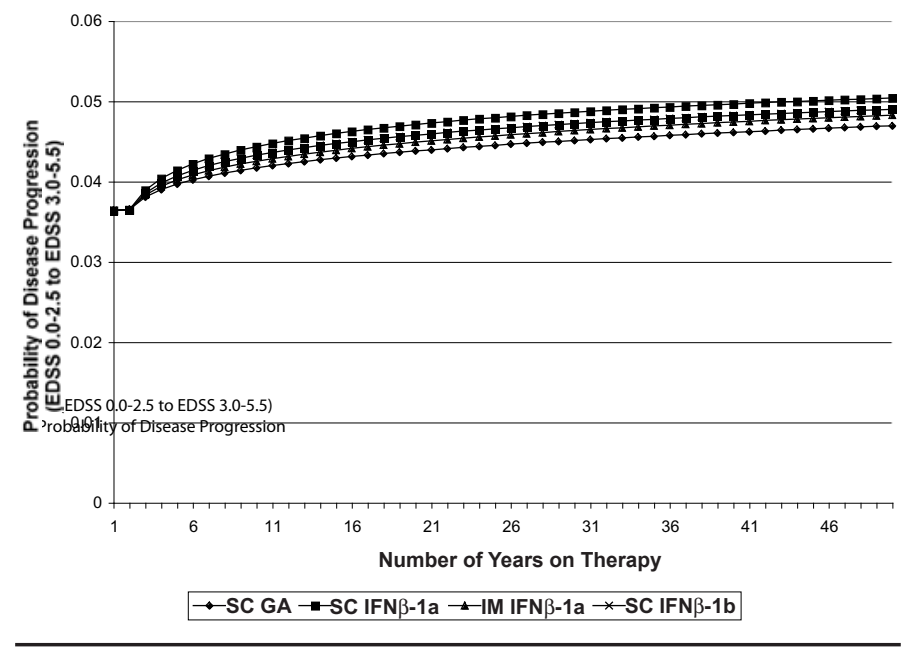

EDSS=Expanded Disability Status Scale (Kurtzke); GA=glatiramer acetate; IFN=interferon; IM=intramuscular; $S C=$ subcutaneous.

\section{Costs}

The model accounted for immunomodulatory therapy acquisition costs, health state-specific MS-related medical costs, and the cost of lost worker productivity. Costs were obtained from the published literature and were inflated to 2005 U.S. dollars, where necessary, by the medical component of the Consumer Price Index. ${ }^{70}$ The annual acquisition cost of SC GA and each $\beta$-interferon was calculated using wholesale acquisition costs (WACs), ${ }^{32}$ days supply per prescription, the recommended dosing schedule, patient compliance (assumed 70\% in basecase model ${ }^{71-73}$ ), patient copayment ( $\$ 25$ per prescription in base-case model), and the proportion of patients discontinuing therapy as reported in clinical trials (see Table 1).

Health state-specific MS-related medical costs were estimated from the previously described Web survey of 711 RRMS patients in the United States. ${ }^{51}$ The resource use and associated costs component of the survey was used in the model and comprised the cost of inpatient care, outpatient care, community services, alterations and equipment, informal care, and medications used to manage the symptoms of MS. Costs were estimated on the basis of Current Procedural Terminology, 4th Edition (CPT-4) codes and corresponding physician fees for each CPT-4 code, diagnosis-related groups, and the Drug Topics Red Book ${ }^{33}$ (WAC prices). Health state and drug costs are presented in Table 2.

\section{Worker Productivity}

Estimates of lost worker productivity were based on the published literature. Specifically, Lichtenberg ${ }^{74}$ estimated the average number of days missed from work for 47 major chronic conditions, including MS. SC GA and $\beta$-interferon-specific estimates of the number of days missed from work (all reasons) were derived via regression analyses of retrospective administrative claims data ${ }^{75}$ and were subtracted from the Lichtenberg baseline value to determine the average number of days missed due to MS for each therapy. The cost of lost worker productivity was estimated as the number of work days missed (in hours) multiplied by an hourly wage and adjusted to account for the proportion of patients employed (Table 2). ${ }^{75,76}$

The model assumed that productivity losses were limited to patients in EDSS 0.0-5.5 and that patients in the later EDSS health states (EDSS >5.5) were not employed. Since the results of the Lage et al. analysis ${ }^{75}$ identified a modest nonsignificant difference in work days missed for the $\beta$-interferons relative to no treatment, the base-case model took these modest differences into account even though they were not statistically significant by using the conservative assumption that the absolute reduction in days lost from work was incurred in comparison with symptom management. Furthermore, while providing an estimate of absenteeism (within the context of a small sample size and including paid time off [PTO]), the Lage et al. analysis ${ }^{75}$ did not provide an estimate of overall lost worker productivity, which includes both absenteeism (lost productivity associated 


\section{Cost-effectiveness of Four Immunomodulatory Therapies for Relapsing-Remitting Multiple Sclerosis:}

A Markov Model Based on Long-term Clinical Data

with missing a work day, excluding PTO) and presenteeism (lost productivity associated with being present at work but performing below expectations). The results reported by Lage et al. provided an estimate of absenteeism that, given the lack of better data, might be used in the model to estimate the impact of MS and its treatments on worker productivity.

\section{Utilities}

Utility weights allow an objective measurement of the desirability of a health state. Utility weights range from 0.0 to 1.0 , where a utility value of 1.0 represents perfect health and a value of 0.0 represents death. These utility values are used to estimate QALYs by multiplying the number of life-years within a particular health state by that health state's utility weight. Utilities were estimated by health state and were obtained from the published literature (Table 2). ${ }^{46,52,77}$ The relapse health states were associated with a 0.094 decrement in utility (e.g., utility for relapse EDSS 0.0-2.5 $=0.824-0.094=0.730)$.

\section{Model Calculations}

The model estimated the following outcomes: average number of years spent in EDSS 0.0-5.5; average number of years spent relapse free; life-years; QALYs; and total costs and costs by component (i.e., immunomodulatory therapy cost, MS-related medical costs, and lost worker productivity costs). Incremental cost-effectiveness ratios (ICERs) were assessed in the model by comparing each of the individual immunomodulatory therapies plus symptomatic management with symptom management. The ICERs were calculated as the difference in costs between 2 treatments divided by the difference in effectiveness: (Cost Drug A - Cost Drug B) / (Effectiveness Drug A - Effectiveness Drug B). The resulting ICERs described the relative cost of purchasing 1 additional unit of relative effectiveness (e.g., cost of 1 additional year spent in the lower EDSS health states). ICERs were calculated for 4 effectiveness measures (cost per QALY; cost per life-year; cost per year spent in the lower EDSS health states [EDSS 0.0-5.5]; and cost per year spent relapse free).

\section{Sensitivity Analyses}

To test the robustness of the model assumptions and specific parameters, univariate sensitivity analyses were performed by increasing and decreasing values for key parameters in the model. Plausible ranges of values were obtained from the published literature or by varying the estimates by up to $25 \%$ in each direction. Parameters analyzed included health state and relapse state utilities; symptomatic treatment costs, health state costs, and drug costs; percentage employed and work days saved; percentage reductions in relapse and disease progression rates in the first 2 years of therapy; changes in relapse and disease progression over time; change in treatment discontinuation over time; EDSS distribution; incidence of NAbs; change in NAbs over time; and discount rates. Sensitivity results for each model input
FIGURE 4 Prediction Curve of the Long-term Probability of Disease Progression (EDSS 3.0-5.5: Moderate Limitations in Mobility to EDSS 6.0-7.5: Walking Aid or Wheelchair Required) While on Immunomodulatory Therapy 12-17,20-23,26,28,63

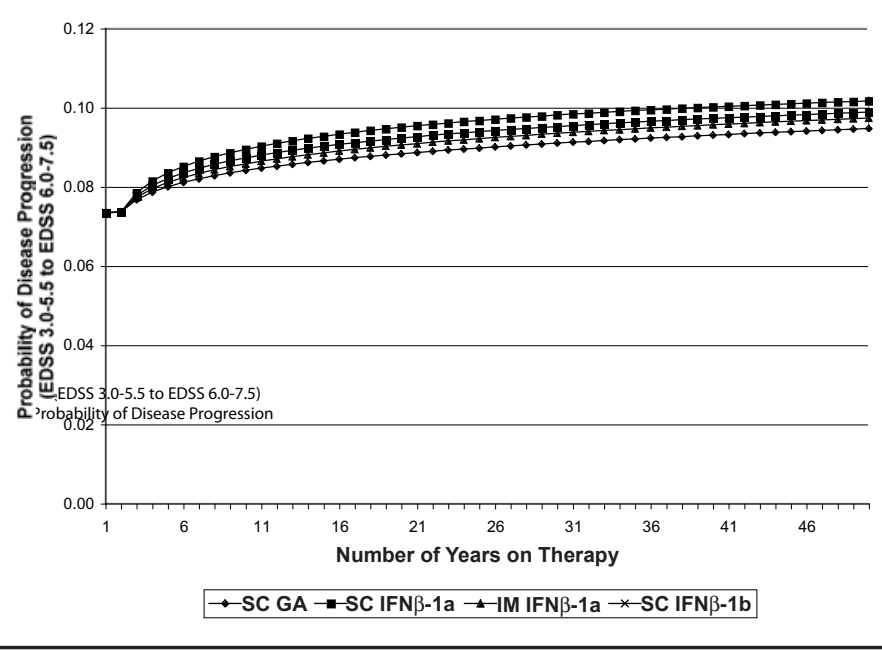

EDSS = Expanded Disability Status Scale (Kurtzke); GA=glatiramer acetate; IFN=interferon; IM=intramuscular; $S C=$ subcutaneous.

assessed were ranked from most sensitive to least sensitive and plotted on a tornado diagram. Results (Figure 5) indicated that changes in health state utilities were the most sensitive model parameter. To further test the sensitivity of the model to changes in health state utilities, 3 analyses were performed: (1) changing all utility values by a relative $\pm 25 \%$; (2) replacing the utility values in the base-case model with European-derived utilities used in previous economic evaluations ${ }^{78}$; and (3) changing only the disutility values associated with the relapse health states by a relative $\pm 25 \%$. Additional scenario-based sensitivity analyses were performed to evaluate the impact on model results of changes to multiple parameters (e.g., simulating assumptions used in previously published MS models). Ranges used in sensitivity analyses (univariate and scenario) are presented in Table 2.

\section{Results}

Total costs per patient over the time horizon of a patient's lifetime were estimated at $\$ 295,586, \$ 352,760, \$ 364,267, \$ 377,996$, and $\$ 358,509$ for symptom management, SC GA, IM IFN $\beta$-1a, SC IFN $\beta-1 a$, and SC IFN $\beta$ - 1 b, respectively (Table 3). MS-related medical costs were the largest cost component (approximately 95\% of total costs in the symptom management arm and $70 \%-75 \%$ of total costsin the immunomodulatory arms), followed by the cost of immunomodulatory therapy (approximately 


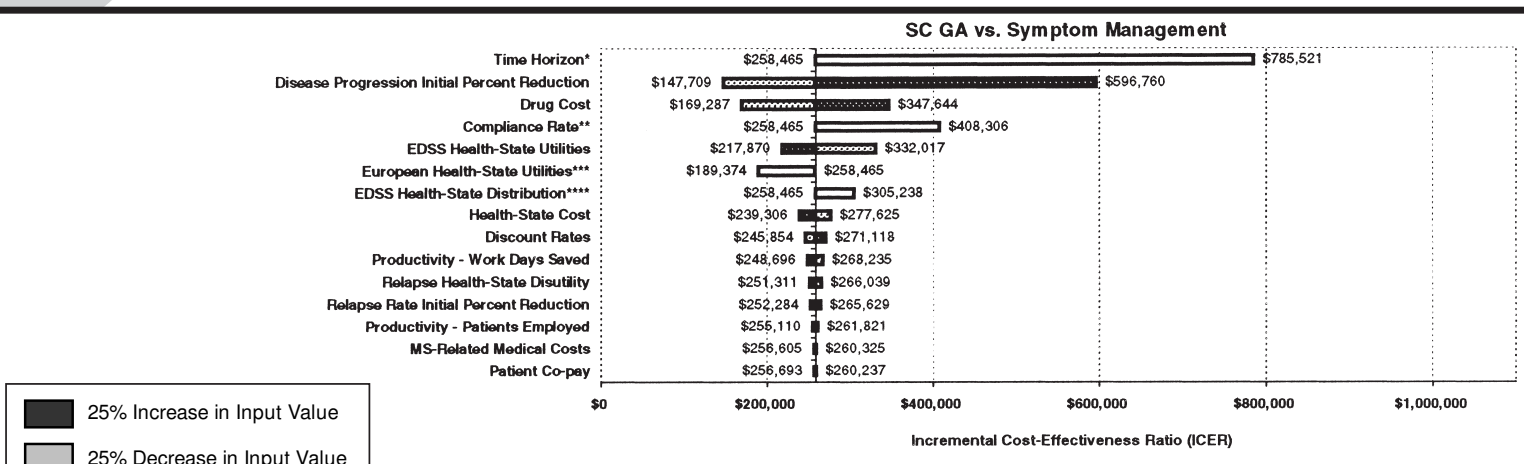

$25 \%$ Decrease in Input Value

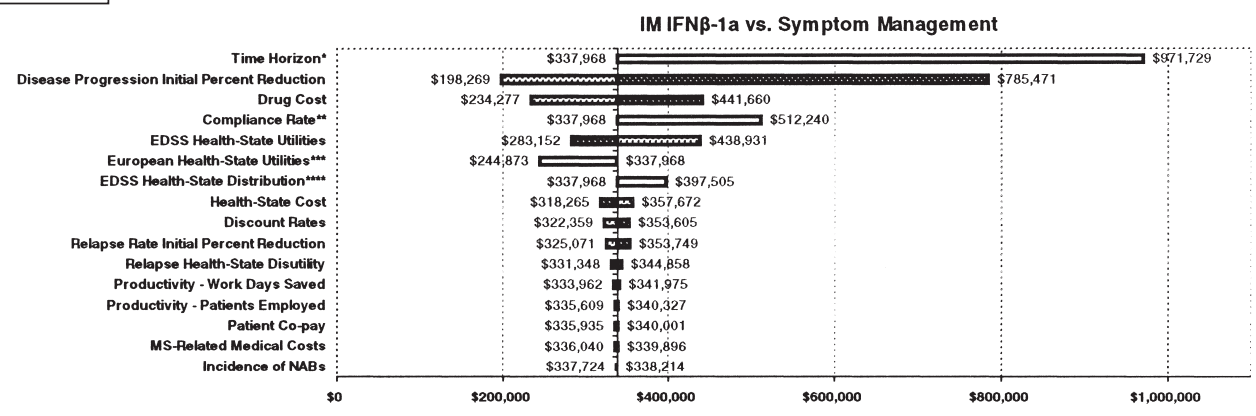

Incremental Cost-Effectiveness Ratio (ICER)
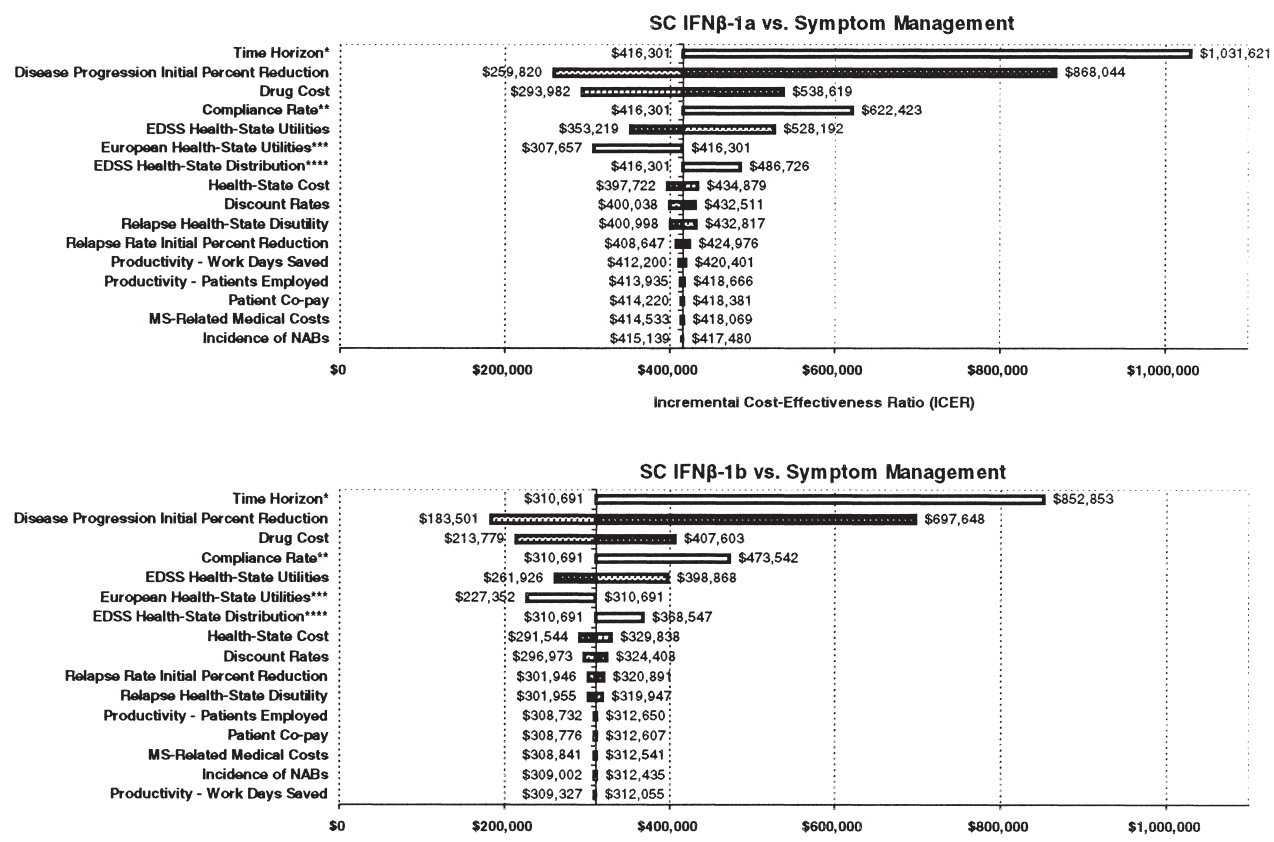

incremental Cost-Effectiveness Ratio (ICER)

Note: Sensitivity analyses were based on two methods of changing values: (1) by $+25 \%$ and $-25 \%$; and (2) by prespecified values. The gray bars present results from method $\# 1$ and the white bars represent results from method \#2. The asterisks are specific to the white bars:

* Time horizon: base case $=$ lifetime; sensitivity analysis $=5$ years.

** Compliance: base case $=70 \%$; sensitivity analysis $=100 \%$.

*** Utility values: base case $=$ U.S. -based values; sensitivity analysis = European-based values.

**** EDSS distribution: base case =across all EDSS health states; sensitivity analysis = all patients start in first EDSS health state (EDSS 0.0-2.5).

EDSS=Expanded Disability Status Scale (Kurtzke); GA=glatiramer acetate; IFN=interferon; IM=intramuscular; MS=multiple sclerosis; NAbs=neutralizing antibodies;

$S C=$ subcutaneous. 


\section{Cost-effectiveness of Four Immunomodulatory Therapies for Relapsing-Remitting Multiple Sclerosis:}

A Markov Model Based on Long-term Clinical Data

20\%-25\% of total costs). Comparing direct medical costs (i.e., MS-related medical costs and immunomodulatory therapy costs) of the symptom management arm with the SC GA, IM IFN $\beta-1 a$, SC IFN $\beta-1 a$, and SC IFN $\beta-1 b$ arms of the model (from Table 3), we found the added cost of immunomodulatory therapy was partially offset by savings in MS-related medical costs, and the greatest cost offsets occurred in the SC GA arm (24\% of the cost of SC GA was offset by savings in MS-related medical costs versus $17 \%-22 \%$ of the cost of the $\beta$-interferons).

Outcomes over the lifetime time horizon assessed in the model were similar across the 4 immunomodulatory therapies and were generally improved compared with outcomes with symptom management (Table 3). The exception was for the estimated life-years gained, as immunomodulatory therapy had little impact on survival other than the slight delay in disease progression to EDSS 10 (death). Comparisons among the 4 immunomodulatory therapies indicated that patients on SC GA had slightly better outcomes relative to patients on the $\beta$-interferons.

Overall, the model indicated that patients on SC GA experienced greater cost benefits compared with patients on any of the $3 \beta$-interferons. The incremental cost per QALY was $\$ 258,465, \$ 337,968, \$ 416,301$, and $\$ 310,691$ for SC GA, IM IFN $\beta-1 a$, SC IFN $\beta-1 a$, and SC IFN $\beta-1 b$, respectively, compared with symptom management. ICERs comparing symptom management with the 4 immunomodulatory therapies for the other outcomes of interest are presented in Table 3.

\section{Sensitivity Analyses}

Overall, univariate sensitivity analyses showed results to be sensitive to changes in health state utilities, the percentage reduction in disease progression rates in the first 2 years of therapy used to estimate immunomodulatory therapy treatment effects, model time horizon, and immunomodulatory therapy acquisition costs (Figure 5). Further assessment of changes to health state utilities revealed that changes to the disutility values associated with the relapse health states had minimal effect on cost-effectiveness results. However, changes to utility values over all health states had a substantial impact. We observed the greatest impact when we changed all utility values by a relative $\pm 25 \%$.

In a scenario in which the model assumed no change in SC GA effects on disease progression in the first 2 years and a $25 \%$ improvement for the $\beta$-interferons, we observed an overall improvement in the cost-effectiveness of the $\beta$-interferons compared with symptom management, and the ICERs for the $\beta$-interferons (vs. symptom management) were more favorable than those of SC GA (vs. symptom management). However, ICERs for the $\beta$-interferons (vs. symptom management) did not improve compared with SC GA (vs. symptom management) when we assumed no change in SC GA effects on relapse in the first 2 years and a $25 \%$ improvement for the $\beta$-interferons.
As expected, shorter time horizons (e.g., 10-20 years) resulted in larger ICERs when we compared symptom management with each of the 4 immunomodulatory therapy arms of the model, as the shorter time horizons did not fully account for all benefits associated with immunomodulatory therapy. Assuming no change in the acquisition cost of SC GA and a 25\% decrease in the acquisition cost of the $\beta$-interferons resulted in more favorable ICERs for the $\beta$-interferons (vs. symptom management) compared with SC GA (vs. symptom management). Finally, changes in the incidence of NAbs had minimal impact on the ICERs of the $\beta$-interferons compared with symptom management.

\section{Discussion}

The present analysis is the first economic model in MS to (1) incorporate long-term data on treatment effects, (2) include the effect of NAbs on the $\beta$-interferons, (3) account for the inherent differences among clinical trial study designs of the immunomodulatory therapies (e.g., via fixed EDSS distribution and single percentage reduction in relapse and disease progression rates in the first 2 years of therapy), and (4) present results in terms of cost-utility (cost per QALY gained) and costeffectiveness (e.g., cost per year spent relapse free or cost per year spent in less severe disease health states). Model results highlight the potential long-term health and economic benefits of treating MS patients with immunomodulatory therapy and indicate that all 4 immunomodulatory therapies are associated with increased benefits compared with symptom management, albeit at higher costs and without consideration of the cost of adverse events. The model indicated that, of the 4 immunomodulatory therapies used to manage MS and in comparison with symptom management, SC GA was the best strategy in terms of outcomes and costs. Sensitivity analysis indicated that the model was sensitive to changes in a number of key parameters, and thus changes in these key parameters would likely influence the estimated cost-effectiveness results.

In a previous U.S.-based cost-effectiveness model conducted by Prosser et $\mathrm{al}^{46}$ the authors concluded that IM IFN $\beta$-la compared with no treatment (i.e., symptomatic treatment) yielded the largest gain in QALYs with an ICER between $\$ 1.8$ and $\$ 2.2$ million per QALY gained. These results were significantly different from that reported in the current analysis and can be attributed to the underlying methodology used to model MS, the most notable aspects of which include assumptions regarding the treatment effects associated with the immunomodulatory therapies, model time horizon, and utility values. In terms of the treatment effects of the immunomodulatory therapies over time, the Prosser model is based on relapse rates and disease progression rates reported in the pivotal clinical trials for the respective drugs. The current analysis supplements the pivotal clinical trials with data from patients initially enrolled in the pivotal trials and followed over time. While both approaches have limitations (pivotal trials in MS are based on a 2-year 


\section{Cost-effectiveness of Four Immunomodulatory Therapies for Relapsing-Remitting Multiple Sclerosis:}

A Markov Model Based on Long-term Clinical Data

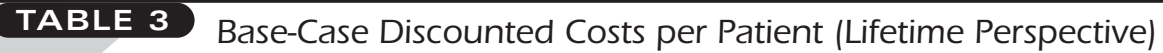

\begin{tabular}{|c|c|c|c|c|c|}
\hline Cost Component & $\begin{array}{c}\text { Symptom } \\
\text { Management }\end{array}$ & SC GA & IM IFN $\beta-1 a$ & SC IFN $\beta-1 \mathrm{a}$ & SC IFN $\beta-1 b$ \\
\hline $\begin{array}{l}\text { Lifetime drug acquisition costs } \\
\text { (average no. of years on therapy) }\end{array}$ & $\begin{array}{c}\$ 0 \\
(\mathrm{~N} / \mathrm{A})\end{array}$ & $\begin{array}{r}\$ 77,340 \\
(13.54)\end{array}$ & $\begin{array}{r}\$ 82,635 \\
(13.05)\end{array}$ & $\begin{array}{l}\$ 95,208 \\
(12.93)\end{array}$ & $\begin{array}{r}\$ 76,957 \\
(13.21)\end{array}$ \\
\hline MS-related medical costs & $\$ 282,950$ & $\$ 264,351$ & $\$ 265,366$ & $\$ 266,839$ & $\$ 265,940$ \\
\hline Productivity costs & $\$ 12,636$ & $\$ 11,069$ & $\$ 16,266$ & $\$ 15,948$ & $\$ 15,611$ \\
\hline Total costs & $\$ 295,586$ & $\$ 352,760$ & $\$ 364,267$ & $\$ 377,996$ & $\$ 358,509$ \\
\hline Average no. of years spent in EDSS 0.0-5.5 & 12.28 & 14.92 & 14.71 & 14.29 & 14.54 \\
\hline Average no. of years spent relapse-free* & 11.42 & 14.67 & 14.24 & 13.98 & 14.15 \\
\hline Life years & 14.791 & 14.819 & 14.818 & 14.815 & 14.817 \\
\hline QALYs & 9.081 & 9.303 & 9.285 & 9.279 & 9.284 \\
\hline $\begin{array}{l}\text { Incremental cost per year spent in EDSS 0.0- } \\
5.5\end{array}$ & - & $\$ 21,667$ & $\$ 28,293$ & $\$ 41,008$ & $\$ 27,860$ \\
\hline Incremental cost per year spent relapse-free & - & $\$ 17,599$ & $\$ 24,327$ & $\$ 32,207$ & $\$ 23,065$ \\
\hline Incremental cost per life-year gained & - & $\$ 2,076,622$ & $\$ 2,588,087$ & $\$ 3,378,626$ & $\$ 2,452,616$ \\
\hline Incremental cost per QALY gained & - & $\$ 258,465$ & $\$ 337,968$ & $\$ 416,301$ & $\$ 310,691$ \\
\hline
\end{tabular}

* Cumulative number of months spent relapse-free converted to years.

$G A=$ glatiramer acetate; IFN=interferon; IM=intramuscular; $M S=$ multiple sclerosis; N/A=not applicable; QALY=quality-adjusted life-year;

$S C=$ subcutaneous; symptom management=symptomatic management alone.

snapshot of a chronic, lifelong condition, and the followup studies are nonrandomized), they represent alternative methods for modeling MS outcomes. It should be noted that the published estimate of effectiveness for IM IFN $\beta$-la is based on those subjects who completed 2 years in the trial at the time it was stopped as opposed to being based on the intent-to-treat population. This approach likely overestimates the true effects of IM IFN $\beta-1 \mathrm{a}$ in this particular trial, which is apparent in results from head-to-head clinical trials of IM IFN $\beta-1 a .18,19$

Sensitivity analyses conducted in the Prosser model, the current analysis, and other MS models have clearly indicated that results are influenced by time horizon, with shorter time horizons associated with less favorable ICERs (e.g., Prosser ${ }^{46}$ and other model $\mathrm{s}^{30,44,78}$ ) and longer time horizons associated with more favorable ICERs (e.g., current analysis, Nuijten and Hutton ${ }^{41}$ ). Guidelines for the conduct of cost-effectiveness analyses (e.g., Academy of Managed Pharmacy, ${ }^{79}$ Canadian Coordinating Office for Health Technology Assessment, ${ }^{80} \mathrm{NICE}^{81}$ ) recommend that pharmacoeconomic models should be sufficiently long to reflect all relevant costs and outcomes, which would suggest that an MS model should adopt a lifetime perspective, given the chronic nature of MS. While guidelines may suggest that a longer time horizon is more appropriate, the managed care perspective often reflects much shorter time horizons (e.g., 1-3 years), which would translate into increasingly less favorable ICERs as the time horizon is shortened. However, as the enrollment base of managed care plans shifts over time, plans are likely to gain and lose MS patients across the spectrum of disability levels. Thus, therapies that reduce relapse and disease progression rates, such as the immunomodulatory therapies for MS, may reduce the burden of MS.

A comparison of the utility values used in the current analysis with that of the Prosser model indicated substantial differences, which are reflected in the ICER results of the individual models. Utilities used in the Prosser model were derived from a U.S. sample of MS patients and members of the general community ${ }^{82}$ and were significantly higher than those reported in a subsequent U.S. study, ${ }^{52,77}$ which were used in the current analysis. The higher utilities contributed to the higher ICERs reported in the Prosser model. The Prosser utilities were also significantly higher than those reported in the United Kingdom and Europe $e^{30,78}$ (e.g., utility assigned to the initial EDSS health state 0.0-2.5 was 0.95 in the Prosser model compared with 0.71 derived from a European population for the same health state ${ }^{78}$, which is reflected in the more favorable ICERs calculated in analyses from other countries..$^{30,40,41}$ It is also of interest that the percentage reduction in utilities from one health state to the next was smaller in the Prosser U.S.-based analyses (e.g., 9\% reduction in utilities from EDSS 0.0-2.5 to EDSS 3.0-5.5 and 12\% reduction in utilities from EDSS 3.0-5.5 to EDSS 6.0-7.5 $5^{46,52,77}$ ) compared 


\section{Cost-effectiveness of Four Immunomodulatory Therapies for Relapsing-Remitting Multiple Sclerosis: A Markov Model Based on Long-term Clinical Data}

with analyses performed in other countries that estimated a 30\% reduction in utilities from EDSS 0.0 to EDSS 3.0 and a similar reduction from EDSS 3.0 to EDSS 7.0..$^{30,78}$

Overall, the majority of economic evaluations in MS, including the current analysis, resulted in ICERs well above the arbitrary and commonly referenced benchmark of $\$ 50,000$ per QALY, even in the "best-case" scenarios used in sensitivity analyses. ${ }^{30,40-46,78,83}$ This was, in part, a reflection of (1) the chronic nature of the disease, (2) survival not being significantly affected by the disease, (3) the modest QALY benefits associated with immunomodulatory therapy in MS versus symptom management, and (4) the high drug acquisition costs of the immunomodulatory therapies. A review of the published costeffectiveness literature revealed a number of analyses of health care interventions that resulted in ICERs above the $\$ 50,000$ per QALY benchmark, including $\$ 1.8$ to $\$ 2.2$ million per QALY as reported in the Prosser MS model ${ }^{46} ; \$ 91,000$ per QALY for osteoarthritis or rheumatoid arthritis patients using diclofenac versus ibuprofen ${ }^{84} ; \$ 110,000$ per QALY for patients using metformin in a diabetes prevention program ${ }^{85} ; \$ 200,000$ per QALY for osteoarthritis or rheumatoid arthritis patients using diclofenac and a proton pump inhibitor versus celecoxib ${ }^{84}$; $\$ 370,000$ per QALY for women with irritable bowel syndrome using alosetron versus no treatment ${ }^{86}$; and $\$ 56,000$ to $\$ 840,000$ per QALY for the use of high-dose erythropoietin versus normal dosages to maintain increased hemoglobin levels (e.g., 12-14 g/ dL). ${ }^{87}$

A review of the cost-effectiveness literature for blood safety interventions (e.g., blood screening and pathogen inactivation) identified a median ICER of $\$ 355,000$ per QALY, ${ }^{88}$ with some results exceeding several million dollars per QALY ${ }^{89}$ While direct comparisons between these studies and the current analysis are limited, the results indicate that not all economic evaluations are bounded by the $\$ 50,000$ per QALY benchmark and that numerous interventions with ICERs well above this threshold have been deemed valuable by patients, health care decision makers, and society. Thus, evaluating the cost-effectiveness of the immunomodulatory therapies in terms of the $\$ 50,000$ per QALY benchmark may not be appropriate.

\section{Limitations}

First and foremost among the limitations of this study is its reliance on clinical trial data. While clinical trial data are considered the preferred source for the basis of parameter inputs used in cost-effectiveness analyses, the MS clinical trials have been criticized for a number of methodological issues. For example, in the Cochrane review of the $\beta$-interferon randomized, placebo-controlled clinical trials, ${ }^{65}$ Rice et al. commented that the quality of the trials was variable with substantial methodological inadequacies. In its review of all immunomodulatory therapy randomized clinical trials for MS, which included SC GA, ${ }^{29}$ NICE noted similar methodological issues concerning randomization, ${ }^{30,40}$ allocation concealment, ${ }^{30,36,40}$ intent-to-treat analysis, ${ }^{30,37,40}$ and last observation carried forward analysis. ${ }^{36}$ Finally, incomplete description of treatment dropouts in the short-term clinical trials likely affected trial results, where if dropouts were deemed to progress (worst-case scenario), the effect of these drugs on relapse and disease progression rates would likely be lost. ${ }^{65}$

Second, our economic analyses did not include the impact of adverse events (e.g., cost and disutility) except to the extent that these might be captured indirectly in the proportion of patients who discontinue therapy (Table 1). However, the cost of treating adverse events would not likely affect the overall results of this analysis since the most common adverse events reported for all 4 immunomodulatory therapies were injection site reactions and influenza-like symptoms, which were generally self-limiting and significantly decreased over time..$^{90,91}$ Nevertheless, these adverse events would likely have an impact on patient utilities, which would influence the cost-effectiveness results. In the Prosser model, treatment-specific disutilities were assigned to account for patient discomfort associated with each treatment, where values ranged from 0.066 for SC GA to 0.204 for SC IFN $\beta-1 b$. These disutilities favored SC GA over the $\beta$-interferons and thus would not likely have changed the model results.

A third limitation arises from the assumption in the model that patients who discontinued immunomodulatory therapy were not allowed to switch to another therapy nor reinitiate therapy at a later time. It is expected that a proportion of patients will discontinue therapy due to worsening of MS symptoms (e.g., as specified by the Association of British Neurologists' guidelines for stopping therapy: 2 disabling relapses within 12 months, secondary progression with increased disability over 6 months, and loss of ability to walk that persists for 6 months ${ }^{92}$ ); however, some patients may discontinue therapy and experience no change in their disability status. On the basis of general clinical practice patterns, these patients would be likely candidates for switching or reinitiating therapy. Had patients been allowed to switch or reinitiate therapy in the model, the calculated ICERs would likely be less favorable for all the immunomodulatory therapies. This assumption (no switching and no reinitiation of therapy) was also adopted in other MS models. ${ }^{30,40,41,46}$ Evidence from real-world observational studies in MS has indicated that from $5 \%^{73,93}$ to $13 \%$ of patients ${ }^{72}$ switched therapy upon discontinuation.

A fourth limitation arises from the assumption in the model regarding the estimation of relapse and disease progression rates associated with the immunomodulatory therapies. To account for differences in the immunomodulatory clinical trials, a fixed patient population was assumed to enter the model (e.g., based on fixed EDSS distribution), and in the first 2 years of therapy, the model assumed that the probabilities of relapse and disease progression used in the symptom management arm were adjusted by a common percentage reduction (relapse: 27\%; 


\section{Cost-effectiveness of Four Immunomodulatory Therapies for Relapsing-Remitting Multiple Sclerosis: A Markov Model Based on Long-term Clinical Data}

disease progression: $30 \%)$. A fitted prediction curve of treatment effects was used to estimate long-term treatment effects of the immunomodulatory therapies. This is a conservative approach to modeling treatment effects over time that uses both the clinical trial and long-term data to predict future outcomes. Previous CEA/CUA studies for the immunomodulatory therapies relied on data from short-term clinical trials and made assumptions to extrapolate treatment effects over time. At the time of the present economic analyses, SC GA was the only immunomodulatory therapy with long-term data collected in a systematic manner over more than 10 years (although it is important to note that by 10 years, $51.2 \%$ of patients eventually withdrew from study follow-up). ${ }^{28}$ Thus, the fitted prediction curve for SC GA may be a better representation of patient outcomes compared with the curves estimated for the $\beta$-interferons, which were based on significantly shorter time horizons (e.g., the longest follow-up was 6 years for SC IFN- $\beta 1$ ).

Fifth, the data used in the present economic analysis are not from comparative, head-to-head clinical trials of the immunomodulatory therapies. Comparative trials of this type, particularly one in which all 4 therapies were evaluated head to head, would be the ideal source of information for the model, but the similarity in outcomes across the 4 therapies suggests that a very large and expensive randomized clinical trial would be necessary in order to observe significant differences among the therapies. Nevertheless, reviews of the individual randomized clinical trials for the 4 immunomodulatory therapies suggest that the therapies have similar short-term effects on relapse and disease progression rates. ${ }^{66}$

Sixth, clinical trials are designed to specifically test the efficacy and tolerability of a particular therapy in a select patient population. The specified inclusion and exclusion criteria of clinical trials may not result in a population that is representative of all patients (e.g., real-world situations). This is especially relevant in MS clinical trials in which patients are selected on the basis of a number of criteria, including having experienced an average of 2 relapses in the previous 2 years, a rate that is relatively higher than that reported for the general MS population (range of 0.14 to 1.1 relapses per year). From the modeling perspective, the clinical trial population is the best available data; however, cost-effectiveness results based on data derived from this population may or may not comport with population-based care and the projection of average economic costs.

\section{Conclusions}

All 4 immunomodulatory therapies used in the treatment of RRMS patients are associated with increased benefits compared with symptom management alone, albeit at higher costs. The pharmacoeconomic model indicated that, of the 4 immunomodulatory therapies used to manage MS and in comparison with symptom management, SC GA was the best strategy. Sensitivity analysis indicated that the model was sensitive to changes in a number of key parameters, and thus changes in these key parameters would likely influence the estimated cost-effectiveness results. While the results of this analysis provide decision makers with health economic information supporting the use of the immunomodulatory therapies, MS is a heterogeneous disease and physicians must select the most appropriate treatment based on the disease characteristics of individual patients. Comparative head-to-head, randomized clinical trials of the immunomodulatory therapies for the treatment of MS are needed to confirm the results predicted by economic models.

\section{What is already known about this subject}

- A number of CEA/CUA evaluations of the immunomodulatory therapies for MS have been published. However, the majority of these evaluations have been conducted from perspectives outside the United States..$^{30,40-45}$ The most recent U.S.-based analysis was the recent CUA evaluation of the immunomodulatory therapies for the treatment of nonprimary, progressive MS (e.g., RRMS and SPMS) over a 10-year time horizon. ${ }^{46}$ Cost-effectiveness results from this analysis, as well as previous evaluations, were considerably higher than the arbitrary and commonly referenced benchmark of $\$ 50,000$ per QALY.

\section{What this study adds}

- The present analysis is the first economic model in MS to (1) incorporate long-term data on treatment effects, (2) include the effect of NAbs on the $\beta$-interferons, (3) account for the inherent differences among clinical trial study designs of the immunomodulatory therapies, and (4) present results in terms of cost-utility (cost per QALY gained) and cost-effectiveness (e.g., cost per year spent relapse free.

- Compared with the U.S.-based model published by Prosser et al. ${ }^{46}$ in 2004, the results from the present analysis are significantly different from that reported by Prosser and can be attributed to the underlying methodology used to model MS, the most notable aspects of which include assumptions regarding the treatment effects associated with the immunomodulatory therapies, model time horizon, and utility values.

\section{DISCLOSURES}

Funding for this research was provided to RTI-Health Solutions by Teva Neuroscience, Inc., and was obtained by authors Christopher Bell, Jonathan Graham, and Stephanie Earnshaw Bell, Graham, and Earnshaw are employed by RTI-Health Solutions, an independent contract research organization that has received research funding from Teva Neuroscience, Inc., for this and other studies and from other pharmaceutical companies that market drugs for the treatment of patients with multiple sclerosis and other medical conditions. Authors MerriKay Oleen-Burkey and Jane Castelli-Haley are employed by Teva Neuroscience, Inc., which manufactures glatiramer acetate. Kenneth Johnson serves as a consultant to Teva Neuroscience, Inc. Oleen-Burkey discloses that she owns stock options in Teva Neuroscience, Inc., as well as stock in Pfizer and other health care companies.

Bell served as principal author of the study. Study concept and design were contributed primarily by Bell and Earnshaw, with input from the coauthors. Data collection was the work of Graham, Castelli-Haley, and Bell, with input from Oleen-Burkey and Earnshaw; data interpretation was the work of Bell, Johnson, and Earnshaw with input from the coauthors. Writing of the manuscript was primarily the work of Bell, Oleen-Burkey, and Castelli-Haley, with input from Earnshaw and Graham; its revision was the work of Bell, Graham, and Johnson, with input from the coauthors. 


\section{Cost-effectiveness of Four Immunomodulatory Therapies for Relapsing-Remitting Multiple Sclerosis: A Markov Model Based on Long-term Clinical Data}

\section{REFERENCES}

1. National Multiple Sclerosis Society. National MS Society Information Sourcebook. 2005. Available at: http://nationalmssociety.org/sourcebook.asp. Accessed November 1, 2005

2. Mayr WT, Pittock SJ, McClelland RL, Jorgensen NW, Noseworthy JH, Rodriguez M. Incidence and prevalence of multiple sclerosis in Olmsted County, Minnesota, 1985-2000. Neurology. 2003;61(10):1373-77.

3. Noonan CW, Kathman SJ, White MC. Prevalence estimates for MS in the United States and evidence of an increasing trend for women. Neurology. 2002;58(1):136-38.

4. Weinshenker BG, Bass B, Rice GP, et al. The natural history of multiple sclerosis: a geographically based study. 2 . Predictive value of the early clinical course. Brain. 1989;112(pt 6):1419-28.

5. Confavreux C, Aimard G, Devic M. Course and prognosis of multiple sclerosis assessed by the computerized data processing of 349 patients. Brain. 1980;103(2):281-300.

6. O'Connor P. Key issues in the diagnosis and treatment of multiple sclerosis. An overview. Neurology. 2002;59(6 suppl 3):S1-S33.

7. Lublin FD, Reingold SC. Defining the clinical course of multiple sclerosis: results of an international survey. National Multiple Sclerosis Society (USA) Advisory Committee on Clinical Trials of New Agents in Multiple Sclerosis. Neurology. 1996;46(4):907-11.

8. Kremenchutzky M, Cottrell D, Rice G, et al. The natural history of multiple sclerosis: a geographically based study. 7. Progressive-relapsing and relapsingprogressive multiple sclerosis: a re-evaluation. Brain. 1999;122(pt 10):1941-50.

9. Richards RG, Sampson FC, Beard SM, Tappenden P. A review of the natural history and epidemiology of multiple sclerosis: implications for resource allocation and health economic models. Health Technol Assess. 2002;6(10):1-73.

10. Rice GPA, Kremenchutzky M, Cottrell DA, Baskerville J, Ebers GC. Observations from the natural history cohort of London, Ontario. In: Filippi M, Comi G, eds. Topics in Neuroscience: Primary Progressive Multiple Sclerosis. Milano: Springer Verlag Italia; 2002.

11. Weinshenker BG, Bass B, Rice GP, et al. The natural history of multiple sclerosis: a geographically based study. I. Clinical course and disability. Brain. 1989;112( pt 1):133-46.

12. Johnson KP, Brooks BR, Cohen JA, et al. Copolymer 1 reduces relapse rate and improves disability in relapsing-remitting multiple sclerosis: results of a phase III multicenter, double-blind placebo-controlled trial. The Copolymer 1 Multiple Sclerosis Study Group. Neurology. 1995;45(7):1268-76.

13. Jacobs LD, Cookfair DL, Rudick RA, et al. Intramuscular interferon beta-la for disease progression in relapsing multiple sclerosis. The Multiple Sclerosis Collaborative Research Group (MSCRG). Ann Neurol. 1996;39(3):285-94.

14. Clanet M, Radue EW, Kappos L, et al. A randomized, double-blind, dosecomparison study of weekly interferon beta-la in relapsing MS. Neurology. 2002;59(10):1507-17.

15. Randomised double-blind placebo-controlled study of interferon beta-la in relapsing/remitting multiple sclerosis. PRISMS (Prevention of Relapses and Disability by Interferon beta-la Subcutaneously in Multiple Sclerosis) Study Group. Lancet. 1998;352(9139):1498-1504

16. Interferon beta-lb is effective in relapsing-remitting multiple sclerosis. I. Clinical results of a multicenter, randomized, double-blind, placebo-controlled trial. The IFNB Multiple Sclerosis Study Group. Neurology. 1993;43(4):655-61.

17. Paty DW, Li DK. Interferon beta-lb is effective in relapsing-remitting multiple sclerosis. II. MRI analysis results of a multicenter, randomized, doubleblind, placebo-controlled trial. UBC MS/MRI Study Group and the IFNB Multiple Sclerosis Study Group. Neurology. 1993;43(4):662-67.

18. Durelli L, Verdun E, Barbero P, et al. Every-other-day interferon beta-1b versus once-weekly interferon beta-la for multiple sclerosis: results of a 2 -year prospective randomised multicentre study (INCOMIN). Lancet. 2002; 359(9316): 1453-60.
19. Panitch H, Goodin DS, Francis G, et al. Randomized, comparative study of interferon beta-la treatment regimens in MS: The EVIDENCE Trial. Neurology. 2002;59(10):1496-1506.

20. Johnson KP, Brooks BR, Cohen JA, et al. Extended use of glatiramer acetate (Copaxone) is well tolerated and maintains its clinical effect on multiple sclerosis relapse rate and degree of disability. Copolymer 1 Multiple Sclerosis Study Group. Neurology. 1998;50(3):701-08.

21. Clanet M, Kappos L, Hartung HP, Hohlfeld R. Interferon beta-la in relapsing multiple sclerosis: four-year extension of the European IFNbeta-la DoseComparison Study. Mult Scler. 2004;10(2):139-44.

22. PRISMS-4: Long-term efficacy of interferon-beta-la in relapsing MS Neurology. 2001;56(12):1628-36.

23. Interferon beta- $1 \mathrm{~b}$ in the treatment of multiple sclerosis: final outcome of the randomized controlled trial. The IFNB Multiple Sclerosis Study Group and The University of British Columbia MS/MRI Analysis Group. Neurology. 1995;45(7):1277-85.

24. Johnson KP, Brooks BR, Ford CC, et al. Sustained clinical benefits of glatiramer acetate in relapsing multiple sclerosis patients observed for 6 years. Copolymer 1 Multiple Sclerosis Study Group. Mult Scler. 2000;6(4):255-66.

25. Johnson KP, Ford CC, Lisak RP, Wolinsky JS. Neurologic consequence of delaying glatiramer acetate therapy for multiple sclerosis: 8-year data. Acta Neurol Scand. 2005;111(1):42-47.

26. Kappos L, Stam Moraga M, Alsop JC. Long-term tolerability of interferon beta-la in relapsing-remitting multiple sclerosis: 6-year safety follow-up of the PRISMS study [abstract P334]. Presented at: Joint Meeting of the Americas and European Committees for Treatment and Research in Multiple Sclerosis; September 18-22, 2002; Baltimore, MD.

27. Kappos L, Traboulsee A, Constantinescu C, et al. Long-term subcutaneous interferon beta-la therapy in patients with relapsing-remitting MS. Neurology. 2006;67(6):944-53.

28. Ford CC, Johnson KP, Lisak RP, et al. A prospective open-label study of glatiramer acetate: over a decade of continuous use in multiple sclerosis patients. Mult Scler. 2006;12:309-20.

29. National Institute for Clinical Excellence. Beta Interferon and Glatiramer Acetate for the Treatment of Multiple Sclerosis. Technology Appraisal Guidance No. 32. London: National Institute for Clinical Excellence; 2002

30. Chilcott J, McCabe C, Tappenden P, et al. Modelling the cost effectiveness of interferon beta and glatiramer acetate in the management of multiple sclerosis. Commentary: evaluating disease modifying treatments in multiple sclerosis. BMJ. 2003;326(7388):522.

31. Goodin DS, Frohman EM, Garmany GP Jr, et al. Disease modifying therapies in multiple sclerosis: report of the Therapeutics and Technology Assessment Subcommittee of the American Academy of Neurology and the MS Council for Clinical Practice Guidelines. Neurology. 2002;58(2):169-78.

32. First Data Bank. Data on file. Teva Neuroscience; 2006.

33. Drug Topics Red Book for Windows. Version 61127. Vol. 36. Montvale, NJ: Thomson PDR 2006; April 2005 release date.

34. Lundy J, Craig BM. The use of disease-modifying agents among multiple sclerosis patients enrolled in Medicare from 1995 to 2002 and the impact of Medicare Part D: analysis of claims data from the Medicare current beneficiary survey. Clin Ther. 2006;28(1):140-45.

35. Whetten-Goldstein K, Sloan FA, Goldstein LB, Kulas ED. A comprehensive assessment of the cost of multiple sclerosis in the United States. Mult Scler. 1998;4(5):419-25.

36. Patwardhan MB, Matchar DB, Samsa GP, McCrory DC, Williams RG, Li TT. Cost of multiple sclerosis by level of disability: a review of literature. Mult Scler. 2005;11(2):232-39.

37. Grima DT, Torrance GW, Francis G, Rice G, Rosner AJ, Lafortune L. Cost and health related quality of life consequences of multiple sclerosis. Mult Scler. 2000;6(2):91-98. 


\section{Cost-effectiveness of Four Immunomodulatory Therapies for Relapsing-Remitting Multiple Sclerosis: A Markov Model Based on Long-term Clinical Data}

38. O'Brien JA, Ward AJ, Patrick AR, Caro J. Cost of managing an episode of relapse in multiple sclerosis in the United States. BMC Health Serv Res. 2003;3(1):17.

39. Orlewska E, Mierzejewski P, Zaborski J, et al. A prospective study of the financial costs of multiple sclerosis at different stages of the disease. Eur J Neurol. 2005;12(1):31-39.

40. Kobelt G, Jonsson L, Fredrikson S. Cost-utility of interferon betalb in the treatment of patients with active relapsing-remitting or secondary progressive multiple sclerosis. Eur J Health Econ. 2003;4(1):50-59.

41. Nuijten MJ, Hutton J. Cost-effectiveness analysis of interferon beta in multiple sclerosis: a Markov process analysis. Value Health. 2002;5(1):44-54

42. Iskedjian M, Walker JH, Gray T, Vicente C, Einarson TR, Gehshan A. Economic evaluation of Avonex (interferon beta-Ia) in patients following a single demyelinating event. Mult Scler. 2005;11(5):542-51.

43. Bose U, Ladkani D, Burrell A, et al. Cost-effectiveness analysis of glatiramer acetate in the treatment of relapsing-remitting multiple sclerosis: first estimates. J Med Econ. 2001;4:207-19.

44. Parkin D, McNamee P, Jacoby A, Miller P, Thomas S, Bates D. A cost-utility analysis of interferon beta for multiple sclerosis. Health Technol Assess. 1998; 2(4):iii-54.

45. Phillips CJ, Gilmour L, Gale R, et al. A cost utility model of beta-interferon in the treatment of relapsing-remitting multiple sclerosis. J Med Econ. $2001 ; 4: 35-50$

46. Prosser LA, Kuntz KM, Bar-Or A, Weinstein MC. Cost-effectiveness of interferon beta-la, interferon beta-lb, and glatiramer acetate in newly diagnosed non-primary progressive multiple sclerosis. Value Health. 2004;7(5):554-68.

47. Hirth RA, Chernew ME, Miller E, Fendrick AM, Weissert WG. Willingness to pay for a quality-adjusted life year: in search of a standard. Med Decis Making. 2000;20(3):332-42

48. Rossman HS. Neutralizing antibodies to multiple sclerosis treatments J Manag Care Pharm. 2004;10(3)(suppl):S12-S19. Available at: http://www. amcp.org/data/jmcp/June04Supplementl.pdf. Accessed March 5, 2007.

49. Kurtzke JF. Rating neurologic impairment in multiple sclerosis: an expanded disability status scale (EDSS). Neurology. 1983;33(11):1444-52.

50. Gold M, Siegel JE, Russell LB, et al. Cost-Effectiveness in Health and Medicine. New York: Oxford University Press; 1996.

51. Oleen-Burkey M, Kobelt G, Borgstrom F. Costs and quality of life of patients with relapsing-remitting multiple sclerosis currently on immunomodulatory therapy in the United States [abstract]. International Committee on Databases in Multiple Sclerosis; 2003.

52. Kobelt G. Economic evidence in multiple sclerosis: a review. Eur J Health Econ. 2004;(5 suppl 1):S54-S62.

53. Kobelt G, Lindgren P, Parkin D, et al. Costs and quality of life in multiple sclerosis: a cross-sectional observational study in the United Kingdom. Stockholm: Stockholm School of Economics; 2000. EFI Research Report No. 398.

54. Kobelt G, Berg J, Atherly D, Hadjimichael O. Costs and quality of life in multiple sclerosis: a cross-sectional study in the United States. Neurology. 2006;66(11):1696-1702

55. Rodriguez M, Siva A, Ward J, Stolp-Smith K, O'Brien P, Kurland L. Impairment, disability, and handicap in multiple sclerosis: a population-based study in Olmsted County, Minnesota. Neurology. 1994;44(1):28-33.

56. Pittock SJ, Mayr WT, McClelland RL, et al. Change in MS-related disability in a population-based cohort: a 10-year follow-up study. Neurology. 2004; 62(1):51-59.

57. MacLurg K, Reilly P, Hawkins S, Gray O, Evason E, Whittington D. A primary care-based needs assessment of people with multiple sclerosis. Br J Gen Pract. 2005;55(514):378-83.

58. Goodkin DE, Hertsgaard D, Rudick RA. Exacerbation rates and adherence to disease type in a prospectively followed-up population with multiple sclerosis. Implications for clinical trials. Arch Neurol. 1989;46(10):1107-12.
59. Weinshenker BG, Ebers GC. The natural history of multiple sclerosis. Can J Neurol Sci. 1987;14(3):255-61.

60. Runmarker B, Andersen O. Prognostic factors in a multiple sclerosis incidence cohort with twenty-five years of follow-up. Brain. 1993;116 (pt 1): 117-34.

61. Centers for Disease Control and Prevention. U.S. vital statistics reports. Table 3. Number of deaths and death rate, by age, race, and sex. 2003;52(3). Available at: http://www.cdc.gov/nchs/data/nvsr/nvsr52/nvsr52_03.pdf. Accessed June 17, 2005

62. Phadke JG. Survival pattern and cause of death in patients with multiple sclerosis: results from an epidemiological survey in northeast Scotland. J Neurol Neurosurg Psychiatry. 1987;50(5):523-31.

63. Simon JH, Jacobs LD, Campion M, et al. Magnetic resonance studies of intramuscular interferon beta-la for relapsing multiple sclerosis. The Multiple Sclerosis Collaborative Research Group. Ann Neurol. 1998;43(1):79-87.

64. Filippini G, Munari L, Incorvaia B, et al. Interferons in relapsing remitting multiple sclerosis: a systematic review. Lancet. 2003;361(9357):545-52.

65. Rice GP, Incorvaia B, Munari L, et al. Interferon in relapsing-remitting multiple sclerosis. Cochrane Database Syst Rev. 2001;(4):CD002002.

66. Khan O, Zabad R, Caon C, Zvartau-Hind M, Tselis A, Lisak R. Comparative assessment of immunomodulating therapies for relapsing-remitting multiple sclerosis. CNS Drugs. 2002;16(8):563-78

67. Kappos L, Clanet M, Sandberg-Wollheim M, et al. Neutralizing antibodies and efficacy of interferon beta-la: a 4-year controlled study. Neurology. 2005; 65(1):40-47.

68. Francis GS, Rice GP, Alsop JC. Interferon beta-la in MS: results following development of neutralizing antibodies in PRISMS. Neurology. 2005;65(1): 48-55.

69. Giovannoni G, Munschauer FE III, Deisenhammer F. Neutralising antibodies to interferon beta during the treatment of multiple sclerosis. J Neurol Neurosurg Psychiatry. 2002;73(5):465-69.

70. Medical Consumer Price Index. Gabriel, Roeder, Smith \& Company. Available at: www.grsnet.con/grs_library/index.html. Accessed June 17, 2005.

71. Frohman EM, Stuve O, Havrdova E, et al. Therapeutic considerations for disease progression in multiple sclerosis: evidence, experience, and future expectations. Arch Neurol. 2005;62(10):1519-30.

72. Tremlett HL, Oger J. Interrupted therapy: stopping and switching of the beta-interferons prescribed for MS. Neurology. 2003;61(4):551-54.

73. Rio J, Porcel J, Tellez N, et al. Factors related with treatment adherence to interferon beta and glatiramer acetate therapy in multiple sclerosis. Mult Scler. 2005;11(3):306-09.

74. Lichtenberg FR. Availability of new drugs and Americans' ability to work. J Occup Environ Med. 2005;47(4):373-80.

75. Lage MJ, Castelli-Haley J, Oleen-Burkey MA. Effect of immunomodulatory therapy and other factors on employment loss time in multiple sclerosis. Work. 2006;27(2):143-51.

76. Busche KD, Fisk JD, Murray TJ, Metz LM. Short term predictors of unemployment in multiple sclerosis patients. Can J Neurol Sci. 2003;30(2):137-42.

77. Kobelt G. Costs and quality of life in multiple sclerosis: a cross-sectional study in the USA. Stockholm: Stockholm School of Economics; 2004. EFI Working Paper Series in Economics and Finance No. 594.

78. Parkin D, McNamee P, Jacoby A, Miller P, Thomas S, Bates D. A cost-utility analysis of interferon beta for multiple sclerosis. Health Technol Assess. 1998; 2(4):iii-54

79. Academy of Managed Care Pharmacy. AMCP Format for Fomulary Submissions, version 2.1. 2005. Available at: http://www.fmcpnet.org/data/resource/ Format Version_2_1 Final_Final.pdf. Accessed January 2, 2007.

80. Canadian Coordinating Office for Health Technology Assessment. Guidelines for economic evaluation of pharmaceuticals: Canada. 2nd ed. Ottawa: Canadian Coordinating Office for Health Technology Assessment (CCHOTA); 1997. 


\section{Cost-effectiveness of Four Immunomodulatory Therapies for Relapsing-Remitting Multiple Sclerosis: A Markov Model Based on Long-term Clinical Data}

81. National Institute for Clinical Excellence. Guide to the Methods of Technology Appraisal. London: National Institute for Clinical Excellence (NICE); 2004.

82. Prosser LA, Kuntz KM, Bar-Or A, Weinstein MC. Patient and community preferences for treatments and health states in multiple sclerosis. Mult Scler. 2003;9(3):311-19.

83. Phillips CJ. The cost of multiple sclerosis and the cost effectiveness of disease-modifying agents in its treatment. CNS Drugs. 2004;18(9):561-74.

84. Maetzel A, Krahn M, Naglie G. The cost effectiveness of rofecoxib and celecoxib in patients with osteoarthritis or rheumatoid arthritis. Arthritis Rheum. 2003;49(3):283-92.

85. Within-trial cost-effectiveness of lifestyle intervention or metformin for the primary prevention of type 2 diabetes. Diabetes Care. 2003;26(9):2518-23.

86. Ladabaum U. Safety, efficacy and costs of pharmacotherapy for functional gastrointestinal disorders: the case of alosetron and its implications. Aliment Pharmacol Ther. 2003;17(8):1021-30.

87. Tonelli M, Winkelmayer WC, Jindal KK, Owen WF, Manns BJ. The costeffectiveness of maintaining higher hemoglobin targets with erythropoietin in hemodialysis patients. Kidney Int. 2003;64(1):295-304.

88. Stone PW, Teutsch S, Chapman RH, Bell C, Goldie SJ, Neumann PJ. Costutility analyses of clinical preventive services: published ratios, 1976-1997. Am J Prev Med. 2000;19(1):15-23.

89. Bell CE, Botteman MF, Gao X, et al. Cost-effectiveness of transfusion of platelet components prepared with pathogen inactivation treatment in the United States. Clin Ther. 2003; 25(9):2464-86.

90. Simpson D, Noble S, Perry C. Glatiramer acetate: a review of its use in relapsing-remitting multiple sclerosis. CNS Drugs. 2002;16(12):825-50.
91. McCormack PL, Scott LJ. Interferon-beta-lb: a review of its use in relapsing-remitting and secondary progressive multiple sclerosis. CNS Drugs. 2004;18(8):521-46.

92. Association of British Neurologists. Guidelines for the use of beta interferons and glatiramer acetate in multiple sclerosis; 2001. Accessed January 2, 2007.

93. O'Rourke KE, Hutchinson M. Stopping beta-interferon therapy in multiple sclerosis: an analysis of stopping patterns. Mult Scler. 2005;11(1):46-50.

94. Rudick RA, Cutter GR, Baier M, et al. Estimating long-term effects of disease-modifying drug therapy in multiple sclerosis patients. Mult Scler. 2005;11(6):626-34.

95. Ebers G, Rice G, Wolf C, et al. 16-year long-term follow-up of interferon beta-1b treatment in RRMS. Neurology. 2005;64(suppl 1):A385.

96. Placebo-controlled multicentre randomised trial of interferon beta-1b in treatment of secondary progressive multiple sclerosis. European Study Group on interferon beta-1b in secondary progressive MS. Lancet. 1998;352(9139): 1491-97.

97. Randomized controlled trial of interferon-beta-la in secondary progressive MS: Clinical results. Neurology. 2001;56(11):1496-1504.

98. Jacobs LD, Beck RW, Simon JH, et al. Intramuscular interferon beta-la therapy initiated during a first demyelinating event in multiple sclerosis. CHAMPS Study Group. N Engl J Med. 2000;343(13):898-904.

99. Cohen JA, Cutter GR, Fischer JS, et al. Benefit of interferon beta-la on MSFC progression in secondary progressive MS. Neurology. 2002;59(5): 679-87. 